\title{
Type 2 diabetes - unmet need, unresolved pathogenesis, mTORC1-centric paradigm
}

\author{
Jacob Bar-Tana ${ }^{1}$ (D) \\ Published online: 4 March 2020 \\ (C) The Author(s) 2020
}

\begin{abstract}
The current paradigm of type 2 diabetes (T2D) is gluco-centric, being exclusively categorized by glycemic characteristics. The gluco-centric paradigm views hyperglycemia as the primary target, being driven by resistance to insulin combined with progressive beta cells failure, and considers glycemic control its ultimate treatment goal. Most importantly, the gluco-centric paradigm considers the non-glycemic diseases associated with T2D, e.g., obesity, dyslipidemia, hypertension, macrovascular disease, microvascular disease and fatty liver as 'risk factors' and/or 'outcomes' and/or 'comorbidities', rather than primary inherent disease aspects of T2D. That is in spite of their high prevalence (60-90\%) and major role in profiling T2D morbidity and mortality. Moreover, the gluco-centric paradigm fails to realize that the non-glycemic diseases of T2D are driven by insulin and, except for glycemic control, response to insulin in T2D is essentially the rule rather than the exception. Failure of the glucocentric paradigm to offer an exhaustive unifying view of the glycemic and non-glycemic diseases of T2D may have contributed to T2D being still an unmet need. An mTORC1-centric paradigm maintains that hyperactive mTORC1 drives the glycemic and non-glycemic disease aspects of T2D. Hyperactive mTORC1 is proposed to act as double-edged agent, namely, to interfere with glycemic control by disrupting the insulin receptor-Akt transduction pathway, while concomitantly driving the non-glycemic diseases of T2D. The mTORC1-centric paradigm may offer a novel perspective for T2D in terms of pathogenesis, clinical focus and treatment strategy.
\end{abstract}

Keywords Type 2 diabetes $\cdot$ Metabolic syndrome $\cdot$ Insulin resistance $\cdot$ Mammalian target of rapamycin (mTOR)

\section{Type 2 diabetes - unmet need}

Type 2 Diabetes (T2D) consists of two stages, pre-diabetes and diabetes, with yearly conversion rate of $5-10 \%$. The two stages are defined by their respective glycemic criteria based on $\mathrm{HbA} 1 \mathrm{C}(5.7-6.4 \% ; \geq 6.5 \%)$, fasting plasma glucose (FPG) $(100-125 \mathrm{mg} / \mathrm{dL} ; \geq 126 \mathrm{mg} / \mathrm{dL})$ or oral glucose tolerance (OGT) (2 h plasma glucose 140-199 mg/dL; $\geq 200 \mathrm{mg} / \mathrm{dL}$ ) [1]. T2D is epidemic, with average global diabetes prevalence of $8.8 \%$ of the world population aged $20-79$ years, and expected to further increase to $9.9 \%$ by the year 2045 [2]. Diabetes prevalence in some countries may reach $30 \%$ of the local adult population. Prevalence estimates for prediabetes vary widely depending on the diagnostic test used, and amounts to $>30 \%$ of world adult population [3].

Jacob Bar-Tana

jacobb@ekmd.huji.ac.il

1 Hebrew University Medical School, 91120 Jerusalem, Israel
Beyond its glycemic presentations, diabetes patients present a variety of highly prevalent non-glycemic diseases that drive T2D morbidity and mortality. Thus, close to $90 \%$ of diabetes adult patients are overweight or obese [4], resulting in the 'diabesity' connotation [5]. About 30-60\% of Western diabetes patients are dyslipidemic (hypertriglyceridemia, small dense LDL-Cholesterol (sdLDL-C), low HDL-C) (6), reaching 60-90\% prevalence in Asian population [7, 8]. Similarly, $60-85 \%$ of diabetes patients are hypertensive [9], and about $60 \%$ present non-alcoholic fatty liver disease (NAFLD) [10]. Moreover, diabetes patients have a significantly higher incidence of Alzheimer disease (AD) [11], and an increased incidence of a variety of cancers (liver, pancreas, colorectal, bladder, breast) [12]. Most importantly, about 30\% of all diabetes patients present with 'macrovascular' (cardio- / cerebro- / peripheral-vascular) disease, being a major cause of morbidity, and accounting for half of all deaths [13]. Concomitantly, T2D patients are inflicted by a variety of 'microvascular' diseases, including diabetic nephropathy (30$50 \%$ prevalence [14]), retinopathy (30\% prevalence [15]), and peripheral polyneuropathy (lifetime prevalence 30-50\% [16]). 
Of note, most of the non-glycemic diseases of T2D are already evident during the pre-diabetes stage of T2D, namely, prior to the appearance of solid hyperglycemia. Thus, most pre-diabetic patients are obese and/or hypertensive and/or dyslipidemic, being classified as non-diabetic Metabolic Syndrome patients [17]. Most importantly, pre-diabetes is already associated with an established cardiovascular disease $[18,19]$, nephropathy [20], neuropathy [21,22], retinopathy [23] and all-cause mortality [24].

In spite of its phenotypic complexity, the current T2D paradigm is fully gluco-centric, being exclusively categorized by its glycemic characteristics. The gluco-centric view of T2D considers hyperglycemia as T2D primary pathology, and glycemic control its ultimate treatment. The other disease aspects of T2D are considered 'risk factors' (e.g., obesity) and/or 'outcomes' (macrovascular disease, microvascular disease, dyslipidemia, NAFLD) and/or 'comorbidities' (e.g., hypertension, cancer, neurodegeneration) (Fig. 1), rather than primary disease aspects of T2D. This gluco-centric view is shared by Diabetologists (1), Pharma, and Regulatory Authorities [25].

In line with the gluco-centric paradigm of T2D, pharmacological treatment focuses on glycemic control, usually initiated upon reaching the hyperglycemic diabetes stage of T2D [1]. Current antidiabetic drugs, except of metformin and thiazolidinediones, consist of agents that promote insulin secretion (sulphonylureas, GLP1 analogs, DPP4i), increase glucose excretion in urine (SGLT2i), or decrease dietary glucose absorption (acarbose), followed by insulin(s). However, in spite of the pharmacological efforts and economic burden [26] made in controlling hyperglycemia, about $40 \%$ of T2D patients still fail to reach glycemic control $(\mathrm{A} 1 \mathrm{C}<7 \%)$ [27-29]. Moreover, failure is more common in patients prescribed insulin(s), whereby $65 \%$ of patients fail to reach glycemic targets [27]. Most importantly, except for pioglitazone

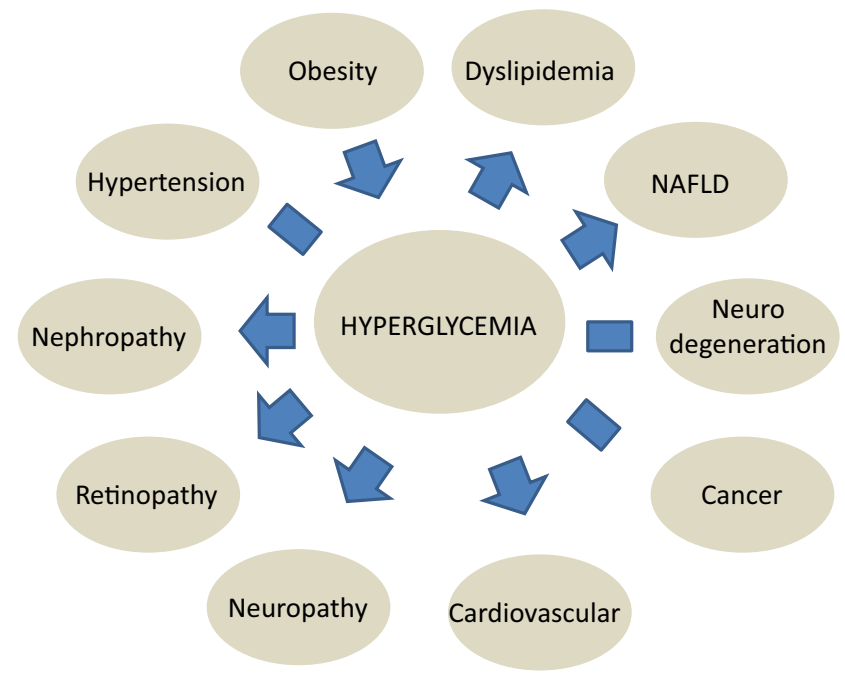

Fig. 1 Gluco-centric paradigm of T2D. Hyperglycemia as T2D primary pathology. The other disease aspects of T2D are considered 'risk factors' and/or 'outcomes' and/or 'comorbidities' (having a limited use due to side effects) and GLP1 analogs, no drug has proved effective in preventing / delaying the progressive failure of beta cells in T2D patients.

Of note, hyperglycemia levels in T2D patients within the $7-10 \%$ HbA1C range are positively associated with risk to develop the macrovascular and/or microvascular diseases of T2D [30]. However, the macrovascular disease is unaffected [31-34] while the nephropathy disease is only mildly affected [35] by anti-diabetic drugs which target hyperglycemia ( $\mathrm{HbA} 1 \mathrm{C}<7.0 \%)$, implying dubious causal association between hyperglycemia levels and the macro- and microvascular diseases of T2D. More surprisingly, intensive glycemic control (HbA1C $6.4 \%$ vs $7.5 \%$ ), accomplished by more use of insulin(s) and oral drug combinations is reported to be associated with increased mortality [31], in particular in T2D patients presenting with diabetic nephropathy [36].

Within the framework of cardiovascular outcome trials (CVOT) required by the FDA since 2008 for proving safety of new anti-diabetic drugs, some GLP1 analogs and SGLT2i proved statistical cardiovascular benefit over placebo in T2D patients with cardiovascular disease [37-39]. In light of their mild glucose lowering efficacy (decrease in $\mathrm{HbA1C}$ of 0.24 $0.58 \%$ ), their cardiovascular benefit remains to be investigated. Most importantly, the number of patients who need to be treated (NNT) for a period of 3-4 years to prevent one cardiovascular MACE outcome by Empagliflozin, Canagliflozin or Liraglutide amounts to 62, 22 and 53, respectively (adapted from ref. 37-39). Similarly, the respective NNT to prevent a hospitalization for heart failure amounts to 71, 31, and 166 (adapted from ref. 37-39), implying a limited efficacy in alleviating the macrovascular disease of T2D patients.

In light of failure to adequately target the macrovascular disease of T2D by hypoglycemic measures, standard of care (SOC) treatments are presently directed to cardiovascular risk factors known to precipitate and drive the macrovascular disease independently of the glycemic context (1). In line with that, T2D patients are routinely prescribed with 1-3 hypolipidemic agents (high-intensity statin, ezetimibe, fibrates, antiPCSK9 antibody [40]), aspirin, and 1-3 hypotensive drugs (beta-blocker, thiazide, Ca-channel blocker, ACEi, angiotensin receptor blocker (ARB)), in addition to 1-6 hypoglycemic agents (metformin, sulphonylurea, DPP4i, SGLT2i, GLP1 analog, acarbose, insulin(s)) [1]. That is in addition to dietary and exercise recommendations [1]. However, the recommended SOC is only partially productive in delaying the diabetes stage of pre-diabetes patients [41] or in alleviating the macrovascular disease of T2D patients [42]. Also, the success in targeting concomitantly the glycemic, dyslipidemic and hypertensive diseases of T2D is less than $25 \%[28,29]$. Also, some of the drugs designed to treat the non-glycemic aspects of T2D (e.g., beta-blockers, thiazides, statins) may counteract glycemic control [43-45]. Most importantly, in spite of the enormous medical efforts and economic burden invested in 
treating T2D, the disease is still progressive resulting in unmet suffering, morbidity and premature death.

\section{Type 2 diabetes - unresolved pathogenesis}

The current pathogenic paradigm for T2D maintains that glycemic control reflects the interplay between insulin availability and the sensitivity / resistance to insulin of the main tissues engaged in carbo-lipid metabolism, namely, liver, muscle and adipose tissue. Insulin availability is mainly determined by pancreatic beta cells capacity, being modulated by the degradation of circulating insulin in liver. Insulin promotes hepatic and muscle glycogenesis, suppresses hepatic gluconeogenesis, drives glucose uptake and its utilization in muscle (mainly) and adipose tissue, and suppresses adipose lipolysis. Hence, peripheral resistance to insulin implies unrestrained hepatic glucose production, and suppression of muscle and adipose glucose uptake, resulting in hyperglycemia. Peripheral resistance to insulin further implies unrestrained adipose lipolysis, resulting in efflux of long-chain fatty acids (LCFA) that may affect liver and muscle carbo-lipid metabolism [46].

The interplay between pancreatic insulin production and peripheral resistance to insulin defines the current pathogenic paradigm of the pre-diabetes and diabetes stages of T2D (Fig. 2). The pre-diabetes stage is considered to reflect progressive peripheral resistance to insulin, being counterbalanced by increased insulin secretion by beta cells. The resultant hyperinsulinemia offsets the peripheral resistance, resulting in maintaining fasting plasma glucose levels within the $<126 \mathrm{mg} / \mathrm{dL}$ range. The diabetes stage that follows reflects failure / insufficiency of beta cells to compensate for the prevailing peripheral resistance to insulin, resulting in progressive hyperglycemia [47].

The current pathogenic paradigm for T2D leaves unanswered the following questions-.

\subsection{Pre-diabetes insulin resistance vs. hyperinsulinemia: Which comes first?}

The classical pathophysiology paradigm of the prediabetes stage of T2D maintains that peripheral insulin resistance comes first, followed by compensatory hyperinsulinemia due to increase in beta cells mass and activity [48]. Indeed, peripheral insulin resistance has been verified in normoglycemic first-degree relatives of diabetes parents, having a very high life-time risk of developing diabetes [49]. However, these individuals present as well with fasting hyperinsulinemia, making it impossible to decide between insulin resistance and hyperactive beta cells as primary driver. Also, claiming resistance as the primary driver calls for a humoral and/or neuronal agent(s) that may mediate between peripheral resistance and beta cells mass and function during the early normoglycemic normolipemic pre-diabetes stage. However, in spite of repeated efforts, no such mediators have yet been definitively identified.

Alternatively, one may argue for beta cells hyperactivity as a primary driver, at least under conditions of nutrient excess, resulting in primary hyperinsulinemia followed by downregulation of peripheral insulin receptors and/or their signaling pathway [50]. Indeed, acute or chronic increase in plasma insulin in healthy normoglycemic subjects results in significant decrease in insulin-stimulated glucose disposal [51, 52], implying that primary hyperinsulinemia may drive insulin resistance. Also, a variety of high-fat diet (HFD) feeding studies in rats and mice demonstrate fasting hyperinsulinemia at the earliest feeding stage prior to any detectable increase in plasma glucose as a surrogate for insulin resistance (50). However, downregulation of insulin receptors by $90 \%$ may still allow for adequate insulin signaling due to spare insulin receptors [53], implying that peripheral insulin resistance must further involve post receptor defects $[54,55]$. However, no agents have yet been identified which may drive post receptor defects due to hyperinsulinemia. Hence, the question of which comes
Fig. 2 Pre-diabetes / Diabetes paradigm of T2D. Peripheral resistance to insulin in the prediabetes stage is counterbalanced by increased insulin secretion by beta cells, resulting in normoglycemia or mild hyperglycemia. Peripheral resistance to insulin in the diabetes stage results in progressive hyperglycemia due to progressive beta cells failure

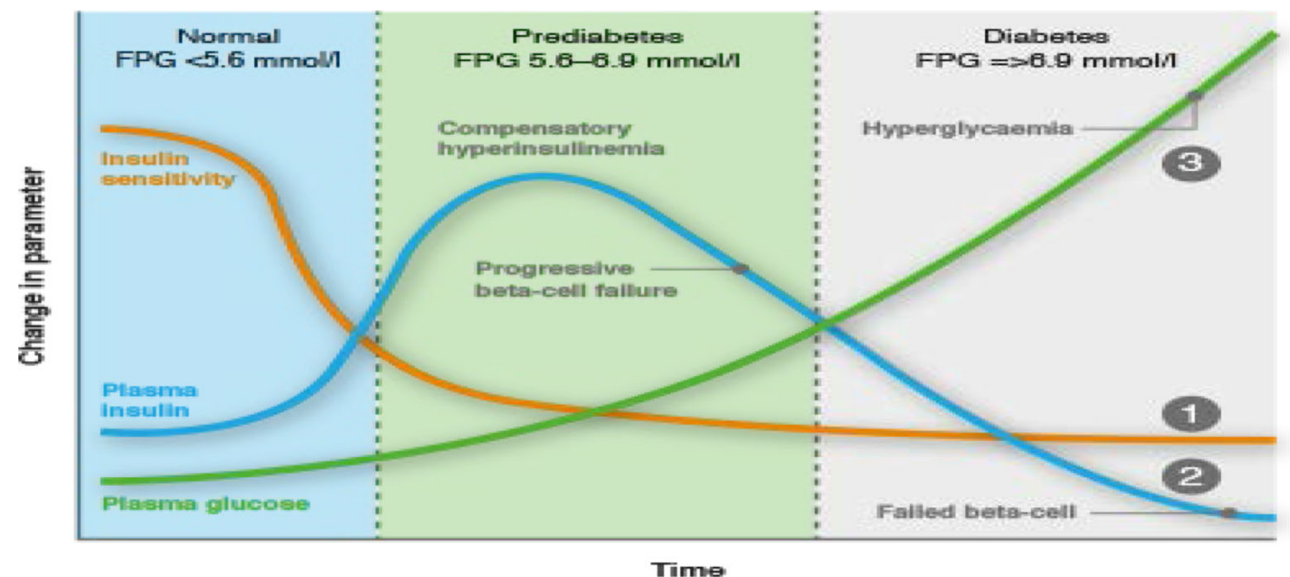


first in driving the pathogenesis of the pre-diabetes stage of T2D still remains unresolved.

\subsection{Selective insulin resistance: The insulin paradox}

Insulin binding to the insulin receptor (IR) results in forming an IR / insulin receptor substrate (IRS) node attached to the plasma membrane. Phosphorylation of IRS tyrosines by the IR tyrosine kinase results in binding sites for the PI3K and its activation, followed by phosphorylating phosphatidylinositol 4,5-bisphosphate (PIP2) to yield the membrane bound phosphatidylinositol 3,4,5-triphosphate (PIP3). PIP3 binds and activates PDK1 which phosphorylates Akt/PKB(Thr308). Further phosphorylation of Akt/PKB(Ser473) by PIP3activated $\mathrm{mTORC} 2$ results in the fully activated phosphoAkt(Thr308, Ser473). Signal termination is achieved by the PIP3 phosphatase PTEN or the protein phosphatases PP2A and PHLPP which dephosphorylate Akt(Thr308) and Akt(Ser473), respectively. The IR-Akt transduction pathway controls carbo-lipid metabolism in response to insulin (Fig. 3). Thus, phosphorylation of glycogen synthase kinase 3 (GSK3) by Akt results in its suppression and in activation of liver and muscle glycogen synthase; phosphorylation of AS160/ TBC1D4 by Akt results in muscle and adipose glucose uptake by translocating GLUT4 to the plasma membrane; and phosphorylation of the transcription factor FOXO1(Thr24,Ser256) by Akt results in its cytosolic sequestration and transcriptional suppression of hepatic gluconeogenesis and adipose fat lipolysis. Hence disruption of the IR-Akt transduction pathway resists insulin action and results in unrestrained hyperglycemia and adipose lipolysis [56].

In addition to the IR/IRS node that drives Akt activation, binding of insulin to IR results in generating the IR/Shc/Grb2/ SOS node that drives the activation of the Ras/RAF/MEK/ Erk1,2/p90RSK transduction pathway. However, Erk1,2/ p90RSK are considered to transduce mitogenic signaling, in contrast to Akt/PKB which controls carbo-lipid metabolism (Fig. 3).

Whereas the IR-Akt transduction pathway may account for insulin resistance in the glycemic context of T2D, other disease aspects of T2D surprisingly present full response to insulin, implying "selective insulin resistance" [57]. The first example of an "insulin paradox" was concerned with hepatic lipogenesis, namely, de novo fatty acids biosynthesis followed by their esterification to yield lipids. Lipogenesis partially accounts for the NAFLD disease of T2D, and proved to be fully responsive to insulin in T2D animal models and patients, in face of resistance to insulin in the glycemic context [57]. Another example has been realized in studying VLDL production in human subjects or animal models. Since insulin suppresses VLDL production [58], IR knockout predicts dyslipidemia. However, IR knockout results in hyperglycemia as expected, but the dyslipidemia of T2D is avoided [59, 60], implying an apparent selective role of the IR in controlling hyperglycemia as contrasted with dyslipidemia.

Several explanations were offered to solve the gluconeogenesis / lipogenesis insulin paradox. These have argued for insulin-independent lipid synthesis $[61,62]$, or hepatic / adipose selective sensitivity to insulin $[63,64]$, or extrahepatic
Fig. 3 IR-Akt transduction pathway. Glycemic control mediated by the IR-Akt transduction pathway

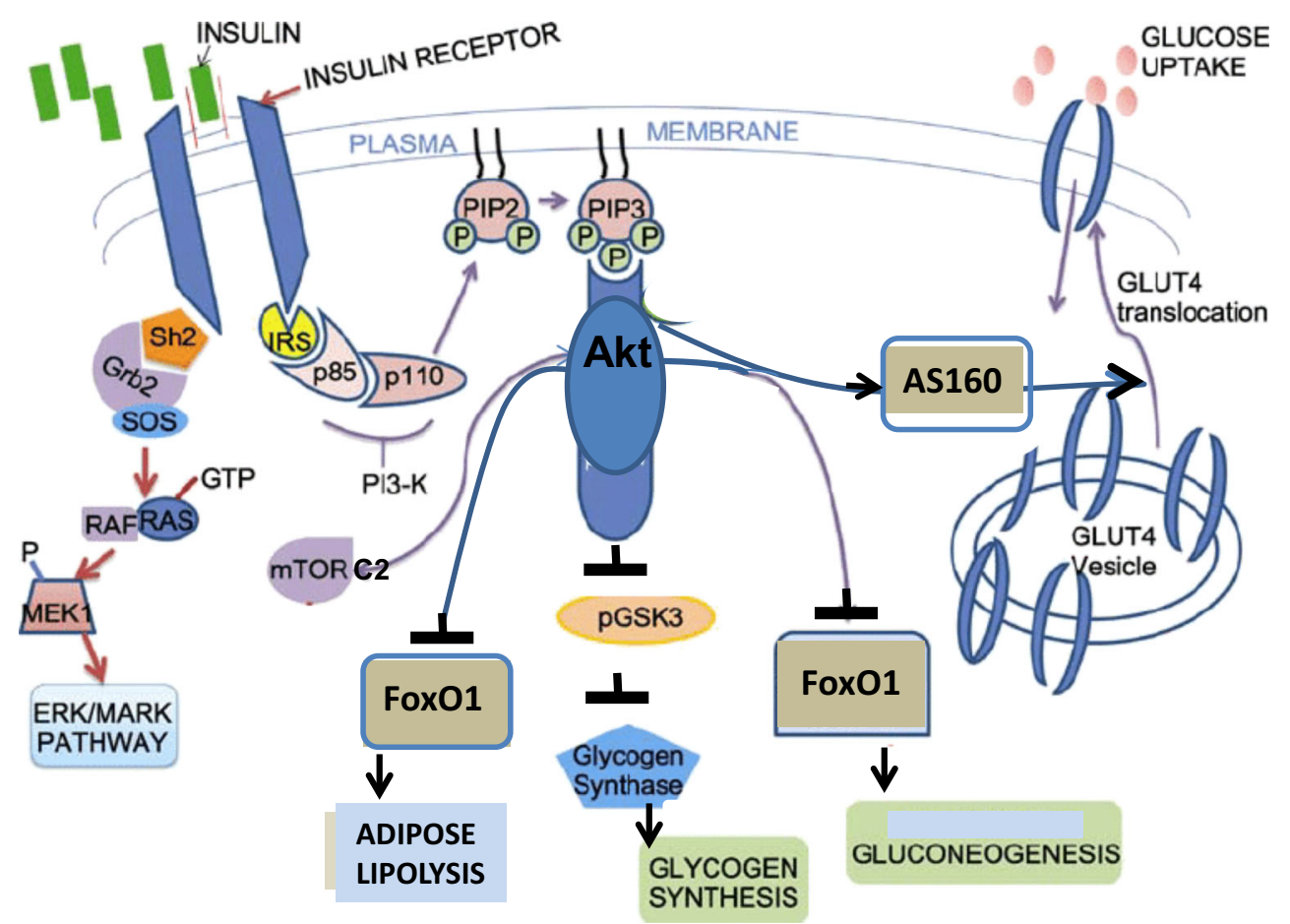


insulin effects (hypothalamic, adipose, pancreatic alpha-cell) [65], or selective / differential activity of Akt in phosphorylating its downstream substrates [66], or hepatic zone specificity of carbo-lipid metabolism [67]. However, all were limited to the glycemic-steatosis paradox, while failing to realize that, except of glycemic control, response to insulin is essentially the rule in $\mathrm{T} 2 \mathrm{D}$, rather than the exception. Indeed, the diabesity of T2D reflects insulin-responsive body weight gain, in face of resistance to insulin in the glycemic and lipolysis context [68-70]. Also, the hypertension disease of T2D reflects insulin-responsive sympathetic activity [71, 72], renal sodium reabsorption [73] and endothelial vasoconstriction [74]. Similarly, T2D hyperuricemia reflects suppression by insulin of renal uric acid clearance [75]. Also, the macrovascular disease of T2D reflects insulin-responsive dyslipidemia [59], hypertension [70-74], diabetic cardiomyopathy [76], vascular smooth muscle cells (VSMC) proliferation, endothelial dysfunction and prothrombosis [77]. Of note, the same tissue may present resistance to insulin in the glycemic context together with response to insulin in a non-glycemic aspect. Hence, the interplay between response and resistance to insulin in shaping the pathogenesis of T2D still remains unresolved, calling for an insulin-dependent, context-dependent, resistance-response unifying paradigm.

\subsection{Insulin resistance and mitochondrial dysfunction: The athlete paradox and the insulin sensitizers riddle}

Insulin resistance has been proposed to be driven by 'mitochondrial dysfunction' with decrease in mitochondria content, size, biogenesis, electron flux and oxidative phosphorylation, and increased oxidative stress $[78,79]$. Indeed, muscle insulin resistance with concomitant mitochondrial dysfunction has been verified in diabetes patients, obese prediabetic subjects, insulin-resistant lean non-diabetic off-springs of T2D parents, insulin-resistant non-diabetic elderly and T2D animal models, implying a putative causal relationship [62]. Mitochondrial dysfunction has been proposed to result in suppression of fatty acid oxidation, followed by their esterification into intrahepatic and intra-myocellular lipids (IMCL) [80]. Intracellular diacylglycerols and oxidative stress are proposed to activate novel PKCs (nPKC) and/or JNK respectively, resulting in serine/threonine phosphorylation of IRS1. Serine/threonine phosphorylation of IRS1 suppresses IRS tyrosine phosphorylation by the IR tyrosine kinase, resulting in disruption of the IR-Akt transduction pathway [62]. Indeed, hepatic steatosis is associated with insulin resistance [81], whereas increased beta-oxidation results in hepatic sensitivity to insulin [82]. However, the IMCL narrative still leaves unresolved the athlete paradox, whereby aerobic exercise is reported to result in increase in IMCL while counteracting muscle insulin resistance [83]. Moreover, the mitochondrial dysfunction narrative still leaves unresolved the insulin sensitizers' riddle, whereby anti-diabetic agents that promote sensitization to insulin e.g., biguanides / metformin, thiazolidinedioones / pioglitazone, high-dose aspirin, berberine and others, are all reported to act as mitochondrial complex I inhibitors [84], implying that 'mitochondrial dysfunction' is more of a solution rather than a problem in the T2D context [85]. Also, mitochondrial ROS is reported by some (but refuted by others) to enhance insulin activity and/or counteract resistance to insulin, rather than exacerbate resistance due to putative oxidative stress [86-89]. Hence, the upstream driver(s) and respective downstream targets that drive insulin resistance by disrupting the IR-Akt transduction pathway still remain unresolved.

\subsection{Hyperactive beta cells vs beta cells failure: The beta cells dilemma}

T2D is considered to follow a two-stage pre-diabetes / diabetes sequence, affixed by a demarcating plasma glucose value of $126 \mathrm{mg} / \mathrm{dL}$, with annual conversion rate of 5-10\% [1, 47]. The pre-diabetes stage is characterized by an increase in beta cells mass and activity, resulting in hyperinsulinemia which offsets peripheral insulin resistance. The pre-diabetes stage is proposed to be followed by progressive beta cells failure and an established diabetes status [1] (Fig. 2), ascribed to low innate beta cells mass [90] and/or stunned beta cells [91]. Beta cells failure may culminate in de-differentiation, mitochondrial dysfunction, ROS production, unfolded protein response (UPR) / endoplasmic reticulum (ER) stress and islet amyloid polypeptide (IAPP) overexpression, followed by glucolipotoxicity and apoptosis $[92,93]$. The two-stage paradigm implies an apparent turning point in T2D pathogenesis and treatment policy. However, concomitantly with beta cells hyperactivity, the pre-diabetes stage presents loss of the firstphase of insulin secretion [94] and about 50\% loss of beta cell number due to apoptosis $[95,96]$. Hence, the pre-diabetes stage presents functional-structural failures which are carried over to, and progress during the hyperglycemic diabetes stage. Thus, similar to peripheral insulin resistance which prevails throughout the course of T2D, beta cells dysfunction and loss progress throughout the pre-diabetes / diabetes continuum, calling for a pathogenic paradigm that may account for beta cells concomitant hyperactivity and failure.

\section{Type 2 diabetes - mTORC1-centric unifying paradigm}

In spite of the advances made in understanding and management of T2D, the disease is progressive, bearing high suffering, morbidity and mortality. Failure to realize the exhaustive pathogenic context of T2D may have contributed to T2D being still an unmet need. The current status calls for a unifying 
paradigm pointing to an upstream defined driver that may generate the multiple disease aspects of T2D, and which may offer an etiology-based target for an exhaustive treatment approach. The paradigm proposed below has been inspired by previous inputs made by David Sabatini [97], Mikhail Blagosklonny [98] and others.

\section{1 mTORC1 $[97,99]$}

The Mammalian target of rapamycin complex I (mTORC1) controls growth and metabolism in response to nutrients, energy and redox status. The mTORC1 complex consists of the mTOR kinase, the core subunits Raptor and mLST8, and the PRAS40 and DEPTOR inhibitory subunits. mTORC1 activation is enabled by two converging arms, namely, mTORC1 attraction to the lysosomal surface, and its activation by the constitutively-attached lysosomal Rheb. These two activation arms are independent, and each is affected by specific upstream effectors.

Binding of mTORC1 to the lysosomal surface via its Raptor subunit is mediated by the lysosomal Rag.GTPase heterodimers, RagA/B and RagC/D. Binding of mTORC1 requires the RagA/B.GTP and RagC/D.GDP conformation, being determined by lysosomal Ragulator, acting as specific GTP exchange factor (GEF) of Rags, and by lysosomal Gator1 and Folliculin-FNIP2 which function as GTPase activation proteins (GAP) for $\mathrm{RagA} / \mathrm{B}$ and $\mathrm{RagC} / \mathrm{D}$, respectively. The Rag arm is affected by a variety of cytosolic and intralysosomal amino acids (e.g., leucine, arginine, glutamine) which bind to specific amino acid receptors (e.g., Sestrin, Castor1, SLC38A9) that interact, directly or indirectly, with the GAPs and/or GEFs that determine Rags conformation. Of importance, the Rag arm may also be activated by glucose [100]. Activation by glucose is mediated by binding of glucose-derived aldolase-bound fructose 1,6-bisphosphate (FBP) to Ragulator, resulting in RagA/B.GTP and its association with mTORC1 $[101,102]$. Hence, the Rag arm mediates mTORC1 activation by amino acids and/or glucose, while suppressing mTORC1 activity in their absence (Fig. 4).

Once attracted to the lysosome, mTORC1 may be activated by lysosomal Rheb.GTP. Rheb may cycle between its active GTP and inactive GDP forms. The GTPase activity of Rheb is modulated by the Tuberous sclerosis complex (TSC), whereby its TSC2 subunit acts as a specific GAP of Rheb. The Rheb arm is activated upon suppressing TSC GAP and/or by suppressing TSC lysosomal attachment. TSC activity may be inhibited by specific phosphorylation of TSC2(Ser939,981,1130,1132,Thr1462) by Akt, resulting in a canonical transduction pathway that leads from insulin/IR to Rheb.GTP and mTORC1 activation [103]. mTORC1 activation by Akt is further complemented by phosphorylation of PRAS40(Thr246) by Akt, resulting in de-repressing mTOR [104]. Most importantly, TSC activity may similarly be inhibited by specific phosphorylation of TSC2(Ser540,644,1798) by activated Erk1,2 and/or p90RSK [105], resulting in an alternative transduction pathway that leads from insulin/IR to Rheb.GTP and mTORC1 activation. The two alternative pathways imply a functional redundancy of the Akt and the Erk1,2/RSK effectors in mediating mTORC1 activation by insulin/IR as well as by other growth factors / RTKs. Also, TSC activity may further be inhibited by specific phosphorylation of TSC2(Ser487,511) by activated IkapaB kinase (IKK) [106], resulting in mTORC1 activation by pro-inflammatory TNFa/TNFR, IL1/IL1R and LPS/TLR4. In contrast, TSC GAP may be activated by specific phosphorylation of TSC2(Ser1345,Thr1227) by AMPK / GSK3beta [107], resulting in suppressing mTORC1 activity by metabolic stress. Suppression of mTORC1 activity by AMPK is further complemented by phosphorylation of Raptor(Ser792) by AMPK [108], resulting in disrupting mTORC1 composition. Similarly to AMPK, multiple different metabolic stresses e.g., hypoxic, deoxy glucose, hyperosmotic, $\mathrm{pH}$, may promote lysosomal TSC2 and/or increase its stability, resulting in inhibition of mTORC1 activity $[109,110]$. Hence, mTORC1 activation is enabled by two converging hits, its lysosomal binding driven by nutrients (e.g., glucose, amino acids), and its activation by lysosomal Rheb.GTP driven by growth factors (e.g., insulin) (Fig. 4). In line with that, TSC1,2 knockout and constitutive RagA.GTP result in constitutive activation of mTORC1 under fasting conditions.

mTORC1 controls growth and metabolism by phosphorylating and/or affecting its downstream targets S6K1, 4EBP, CRTC2, lipin, ATF4, HIF1a, PPARg, PPARa, ULK1, TFEB and others [97, 99]. Phosphorylation of S6K1 and 4EBP results in ribosome biogenesis and in initiating CAP-dependent mRNA translation. Phosphorylation of CRTC2 and lipin results in activating the transcription factor SREBP and in driving lipogenesis and lipid synthesis. Phosphorylation of ATF4 and S6K1 results in purine and pyrimidine biosynthesis, respectively. Activation of HIF1a and SREBP transcription factors results in enhancing glycolysis and the pentose shunt. PPARg activation by mTORC1 promotes adipogenesis, while PPARa inhibition by mTORC1 suppresses fatty acid oxidation and ketogenesis. mTORC1 controls $\mathrm{G} 1 / \mathrm{S}$ transition and G2/M progression. Most importantly, phosphorylation of the ULK1 kinase, Atg13 and the TFEB transcription factor by mTORC1 blocks autophagy and lysosome biogenesis. Not all immediate downstream targets of mTORC1 have presently been verified. However, downstream targets of mTORC1 may be inferred by their response to mTORC1 inhibitors (below).

Some mTORC1 activities in the T2D context are transduced by interacting with mTORC2. The mTORC 2 complex consists of the mTOR kinase, mLST8, Rictor (instead of mTORC1 Raptor) mSin1, Deptor and Protor [97, 99]. mTORC2 phosphorylates and activates Akt(Ser473), the AGC protein kinases (PKA, PKG, PKC) and Serum and 


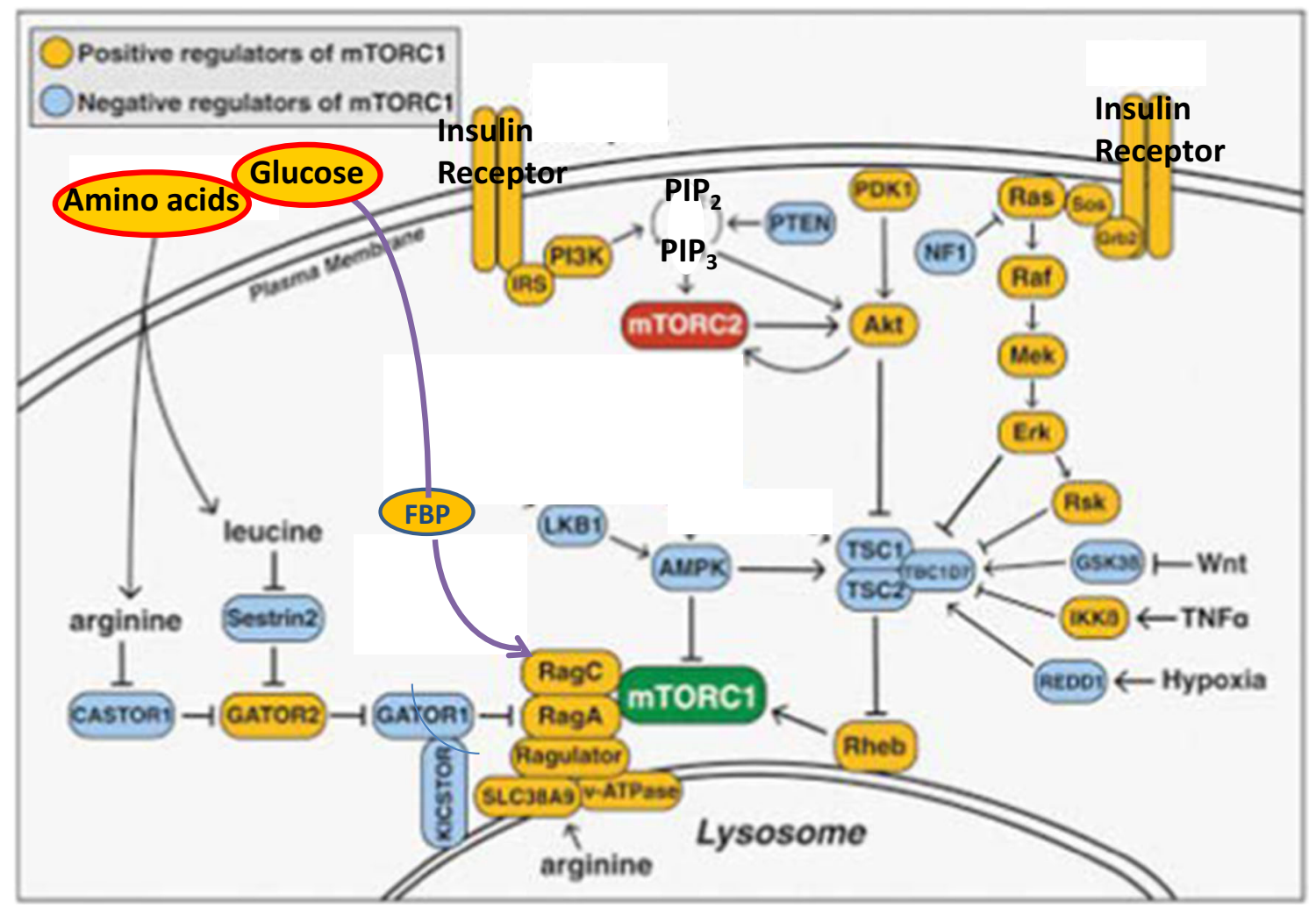

Fig. 4 mTORC1. Binding of mTORC1 to the lysosomal surface is activated by glucose and/or amino acids, being mediated by lysosomal Rag.GTPase heterodimers. Lysosomal mTORC1 is activated by lysosomal Rheb.GTP, being activated by insulin via the IR-Akt and/or the IR-Erk/RSK transduction pathways. FBP - Fructose bi-phosphate glucocorticoid kinase (SGK). mTORC2 activity is inhibited by phosphorylation of its $\mathrm{mSin} 1$ and Rictor subunits by S6K1, thus forming a negative feedback loop whereby activation of mTORC1 by Akt results in inhibition of Akt due to suppression mTORC2 activity by S6K1.

mTORC1 activity may be blocked by rapamycin and respective rapalogs. Rapamycin forms a complex with the FK506-binding protein (FKBP12), and the complex binds to the FRB domain of mTOR, resulting in allosteric inhibition of mTORC1. Hence, response to rapamycin may imply an apparent involvement of mTORC1. However, chronic exposure to rapamycin may also inhibit $\mathrm{mTORC} 2$, resulting in a false positive inference of mTORC1 involvement [111]. Also, not all mTORC1 downstream targets are affected by rapamycin (e.g., 4EBP), and lack of response to rapamycin may result in a false negative inference of mTORC1 involvement [112]. mTORC1 and mTORC2 may both be inhibited by mTOR kinase inhibitors (e.g., Torin).

\section{2 mTORC1-centric paradigm of T2D}

mTORC1 activity may present two pathological extremes, namely, lack-of-function due to mutation of one of its core subunits, and gain-of-function due to genetic constitutive activation of its main drivers (e.g. RagA/B.GTP, Rheb.GTP). In between the two respective mutational extremes, wildtype mTORC1 activity may range between less- and hyper- active kinase, as function of metabolic stress and energy excess, respectively. T2D is proposed to be primarily driven by chronic whole body hyper activation of mTORC1, induced by nutrients / energy excess / metabolites which concomitantly activate the RagA/B.GTP and the Rheb.GTP drivers of mTORC1. In line with that, T2D may be alleviated by suppressing mTORC1 hyper activation. Specifically, mTORC1 hyper activation may be driven by chronic dietary carbohydrate excess of high glycemic index, resulting in concomitant activation of the glucose-induced RagA/B.GTP and the insulin-induced Rheb.GTP drivers of mTORC1. Hyper activation of mTORC1 may similarly be driven by chronic dietary excess of proteins rich in leucine and arginine. These amino acids may stimulate insulin secretion, resulting concomitantly in amino acid-induced RagA/B.GTP and insulin-induced Rheb.GTP. In line with that, caloric restriction, in particular carbohydrate restriction, may inhibit mTORC1 activity by repressing the Rag and Rheb arms due to nutrient and insulin restriction, respectively. Of note, modulation of mTORC1 activity by nutrients / energy excess / metabolites may further be affected by genetic and/or epigenetic and/or tissue and/or context-dependent factors that may determine the sensitivity of the Rag and Rheb arms to respective environmental / 
metabolic / nutrient conditions. Also, primary metabolic effects due to hyperactive mTORC1 may further be modulated by downstream secondary outcomes.

\subsection{Glycemic context of T2D. Resistance to insulin}

Peripheral resistance to insulin in the glycemic context is proposed to be driven by disruption of the IR-Akt transduction pathway by hyperactive mTORC1 and its downstream S6K1 in liver, muscle and adipose tissue, namely, the main organs that control glucose production and its utilization. Thus, phosphorylation of IRS1(Ser307, 1101) by hyperactive S6K1, and phosphorylation of IRS1(Ser636/639, 422) by hyperactive mTORC1, result in suppressing IRS tyrosines phosphorylation by the IR tyrosine kinase, followed by IRS ubiquitination and degradation [113-115]. Also, phosphorylation of GRB10 by hyperactive mTORC1 results in disrupting IR/IRS by phospho-GRB10 [116, 117]. The IR-Akt transduction pathway is further disrupted by inhibition of Akt(Ser473) phosphorylation by mTORC2, due to suppression of mTORC2 kinase activity by hyperactive S6K1 [118, 119] (Fig. 5). Disruption of the IR-Akt pathway by hyperactive mTORC1/ S6K1 results in liver and muscle glycogenolysis, liver gluconeogenesis, GLUT4 sequestration and unrestrained hyperglycemia. In line with that, genetic deletion of S6K1 protects mice from HFD-induced diabetes [120, 121]. Hence, resistance to insulin in the glycemic context is proposed to be congruent with mTORC1/S6K1 hyper activation.

\subsection{Non-glycemic context of T2D. Response to insulin}

Disruption of the IR-Akt transduction pathway by hyperactive mTORC1 may still allow for sustained hyper activation of mTORC 1 by insulin, being mediated by the IR/Ras/Raf/

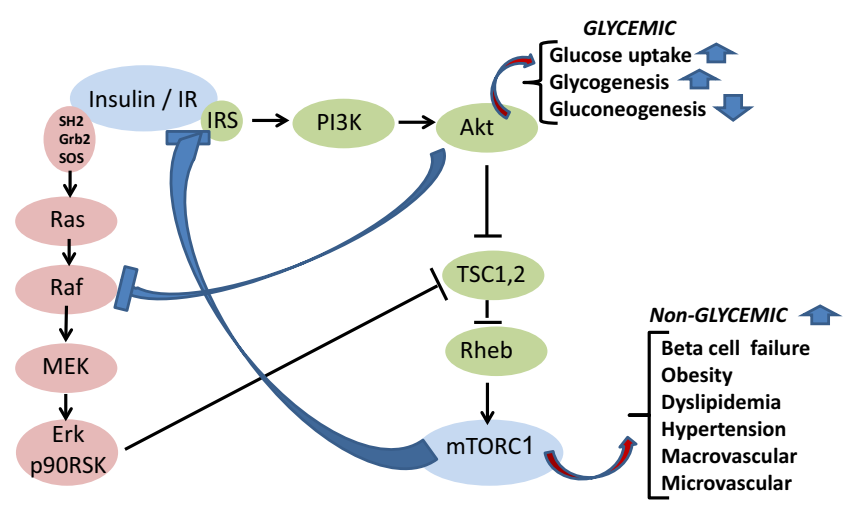

Fig. 5 Resistance and response to insulin by mTORC1. Hyperactive mTORC1 inhibits the IR-Akt transduction pathway resulting in resistance to insulin and deranged glycemic control. Concomitantly, insulin-induced hyperactivation of mTORC1 by the IR-Erk/RSK transduction pathway drives the non-glycemic diseases of T2D. Inhibition of the IR-Akt transduction pathway by hyperactive mTORC1 results in activating the IR-Erk/RSK pathway and in mTORC1 hyper activation
MEK/Erk/p90RSK/TSC/Rheb/mTORC1 transduction pathway, implying redundancy of IR-Akt and IR-Erk/RSK in activating mTORC1 [122, 123] (Figs. 4, 5). Moreover, the reciprocal relationship between the IR-Akt and the IR-Erk/RSK pathways, due to inhibitory phosphorylation of Raf(Ser259) by activated Akt [124, 125], implies enhancement of the IRErk/RSK activity upon inhibiting the IR-Akt pathway by hyperactive mTORC1. Hence, in face of resistance to insulin in the glycemic context, insulin-driven Erk/RSK may transduce a variety of mTORC1-mediated disease aspects of T2D (e.g., beta cell failure, obesity, NAFLD, dyslipidemia, hypertension, diabetes macro- and micro-vascular disease) as outlined below (Fig. 5). Indeed, IR knockout results in hyperglycemia, but also in protecting from non-glycemic diseases of T2D [59], implying an obligatory role for insulin and IR in driving the non-glycemic diseases of T2D.

Progressive beta cells failure The IR-Erk/RSK transduction pathway is fully active in beta cells $[126,127]$, allowing for mTORC1 hyper activation in beta cells in response to nutrient excess, independently of the IR-Akt transduction pathway. Thus, nutrient excess is proposed to account for both, peripheral resistance to insulin in the glycemic context due to suppression of the IR-Akt transduction pathway by hyper active mTORC1 in liver, muscle and adipose tissue (III3), with concomitant increase in insulin production due to IR-Erk/RSKinduced mTORC1 hyper activation in beta cells. Of note, the concomitant hyper activation of mTORC1 in beta cells, liver, muscle and adipose tissue, makes redundant the question of which precedes which, and the search for respective mediators that may generate the insulin resistance / hyperinsulinemia phenotype during the pre-diabetes phase of T2D (Section 2.1).

However, the increased production of insulin and its IAPP by-product by beta cells hyperactive mTORC 1 may result in unfolded protein response (UPR), aimed at counteracting excess synthesis by suppressing protein synthesis and/or eliminating surplus. Elimination of surplus protein is accomplished by autophagy/lysosomal and/or proteasomal degradation. These degradation outlets are blocked by hyperactive mTORC1 [128], resulting in progressive ER stress followed by apoptosis [129]. Also, disruption of beta cells IR-AktFOXO1 pathway by hyperactive mTORC1 results in suppressing PDX and beta cells survival [130]. Hence, hyper activation of beta cells mTORC1 during the pre-diabetes phase of T2D serves as double-edged driver, allowing for beta cells high performance, while concomitantly promoting ER stress and beta cells apoptosis [131]. These two concomitant contrasting aspects of hyperactive mTORC1 may dynamically evolve during the clinical sequel of T2D, whereby the hyperplastic-hypertrophic initial feature yields progressively to an apoptosis outcome $[131,132]$. Of note, the doubleedged profile driven by hyperactive mTORC1 in beta cells throughout the pre-diabetes and diabetes phases of T2D, 
questions the rational of drawing a pathological/etiological demarcation border between the two T2D stages.

Diabesity $90 \%$ of adult T2D patients are overweight or obese [4]. Increased bodyweight, and in particular visceral fat, is usually considered to be etiological in inducing insulin resistance and T2D, due to increase in adipose inflammatory agents (e.g. M1 macrophages, TNFa, IL6) and decrease in adipose adiponectin [133]. Others have argued for a protective effect of adiposity due to bypassing fat deposition in liver and muscle. The mTORC1-centric paradigm proposed here considers the obesity aspect of T2D to be a primary reflection of whole body hyper activation of mTORC1. The obesity disease is proposed to be induced and promoted by primary hyperactive hypothalamic $\mathrm{mTORC} 1$, resulting in disrupting the hypothalamic IR-Akt-FOXO1 transduction pathway which positively and negatively controls hypothalamic POMC/CART and NPY/AgRP, respectively [134, 135]. This will result in an orexigenic drive, suppression of energy expenditure, and disruption of net caloric balance. Increase in bodyweight gain is proposed to be further promoted by adipose hyperactive mTORC1/S6K1, resulting in PPARg-induced adipogenesis [136], SREBP-induced lipogenesis $[137,138]$ and suppression of ATGL-induced adipose lipolysis [139].

NAFLD Most ( $\sim 60 \%)$ T2D patients present with NAFLD [10]. Hepatic steatosis is due to active lipogenesis and suppression of LCFA oxidation. Lipogenesis and fatty acid esterification are transcriptionally controlled by SREBP, being activated by CRTC2 phosphorylation by hyperactive mTORC1 [137, 138]. Hepatic steatosis is proposed to be further promoted due to suppression of PPARa-induced beta-oxidation by hyperactive mTORC1 [140]. Hence, rather than presenting an insulin paradox (Section 2.2), the NAFLD / steatosis aspect of T2D reflects the double-edged activity of mTORC1 in promoting non-glycemic diseases of T2D while interfering with glycemic control. mTORC1 involvement in promoting liver fibrosis and cancerous transformation may account for the further progression of NAFLD to the cirrhosis and HCC stages, respectively.

Dyslipidemia Most (60-90\%) T2D patients are dyslipidemic [6-8]. T2D dyslipidemia triad (hypertriglyceridemia, increase in sdLDL-C, decrease in HDL-C) is driven by increase in VLDL-triglycerides (VLDL-TG) [141]. Increase in VLDLTG is driven by hyperactive mTORC1 due to promoting hepatic steatosis, phosphatidylcholine synthesis [142], and disruption of the IR-Akt-FOXO1 pathway. FoxO1 activation results in transcriptional activation of the microsomal TG transfer protein (MTP) [143] and apoCIII [144]. MTP combines the VLDL ingredients to form the lipoprotein particle, and apoCIII suppresses plasma VLDL-TG lipolysis by lipoprotein lipase [141]. Of note, T2D dyslipidemia is avoided upon knocking out the IR [59], implying an obligatory role for insulin in promoting T2D dyslipidemia [60].

Hypertension Most (60-85\%) T2D patients are hypertensive [9]. Moreover, non-diabetic, non-obese hypertensive subjects present deranged glycemic control [145], indicating a putative common driver for T2D and essential hypertension. Indeed, hyperactive mTORC1 controls the three elements that determine blood pressure, namely, blood volume, vascular sympathetic tone and cardiac function. Fluid volume is controlled by renal sodium reabsorption carried out in the proximal and collecting duct by the apical passive $\mathrm{Na} / \mathrm{H}$ NHE3 and $\mathrm{ENaC}$ transporters, respectively [146]. The apical transport flux is driven by basolateral $\mathrm{Na} / \mathrm{K}$ ATPase [147], being controlled by the IR-Erk/RSK-transduced hyperactive mTORC1 [148-150]. Hypothalamic mTORC1 controls sympathetic tone [151], implying an increase in vascular tone and cardiac output. Increase in sympathetic vascular tone is further aggravated by vasoconstriction due to endothelial dysfunction (below). Chronic hypertension induces mTORC1-driven myocardial hypertrophy with increase in cardiac function, resulting eventually in heart failure. Hence, hyperactive mTORC1 may control the multiple drivers of T2D hypertension.

Macrovascular disease The macrovascular disease accounts for half of all deaths of T2D patients [13]. The macrovascular disease is driven by two independent pathologic processes, namely, atherosclerotic cardiovascular disease (ASCVD) [152] and diabetic cardiomyopathy [153].

ASCVD is driven by endothelial dysfunction, resulting in infiltration and retention of sub-intimal VLDL/sdLDL remnants, followed by sub-intimal recruitment of monocytes / macrophages. Inflammatory cytokines (e.g., IL6, CRP, $\mathrm{TNFa}$ ) produced by activated macrophages induce proliferation of vascular smooth muscle cells (VSMC), their attraction to the sub-intimal layer and their transformation into collagen secreting cells. Disruption of the fibrous cap of the lipidfibrous plaque by macrophages elastase, metalloproteinase and collagenase results in thrombus formation and coronary occlusion $[152,154]$. Hence, the ASCVD aspect of T2D is driven by diabetic dyslipidemia combined with diabetic endothelial dysfunction. Endothelial dysfunction is due to suppression of eNOS due to disruption of the IR-Akt pathway by hyperactive mTORC1 [155].

Diabetic cardiomyopathy is characterized by cardiac dysfunction and heart failure, not accounted for by coronary artery disease or hypertension [156]. It is driven by early left ventricle hypertrophy followed by systolic/diastolic dysfunction, reduced ejection fraction and increase in myocardial fibrosis and apoptosis. Diabetic cardiomyopathy may be improved by promoting cardiac autophagy or by rapamycin 
[157], implying a putative pathogenic role of hyperactive mTORC1. Hence, the macrovascular disease of T2D is proposed to be orchestrated by insulin-induced hyperactive mTORC1.

Microvascular diseases: Nephropathy, retinopathy, neuropathy Diabetic nephropathy is characterized by detachment of glomerular podocytes from the epithelial basement membrane followed by their loss, and loss of proximal tubule cells. The combined loss results in albuminuria due to podocytes failure to filter out plasma albumin, and failure of proximal tubule cells to reuptake urinary albumin. Diabetic nephropathy may be delayed / prevented by IR knockout [158], or rapamycin treatment [159], or curtailing podocytes' mTORC1 copies $[160,161]$, or by suppressing Akt activity in proximal tubular cells [162], implying a role for insulin-activated mTORC1 in driving diabetic nephropathy.

Diabetic retinopathy consists of non-symptomatic non-proliferative first stage retinopathy, followed by second stage proliferative neovascularization. The proliferative stage consists of extensive angiogenesis of leakage-prone blood vessels [163] driven by HIF 1a-induced VEGF. HIF 1 a may be induced under normoxic conditions by hyperactive mTORC1 [164, 165].

Diabetic peripheral neuropathy is driven by decrease in density of small un-myelinated or thinly-myelinated intra epidermal nerve fibers (IENF) which originate in the dorsal nerve root ganglia and mediate pain, temperature sensation or autonomic functions. Hyperactive mTORC1 is reported to interfere with synaptic plasticity and to induce chronic neuropathy $[166,167]$. In line with that, suppression of mTORC1 activity is reported to result in anti-nociceptive effects in experimental models of inflammatory and neuropathic pain [166-168].

Comorbidities T2D is associated with increased risk of cancers (PDAC, CRC, breast, other), neurodegeneration (AD, Parkinson), psoriasis, poly cystic ovary syndrome (PCOS), other. Hyperactive mTORC1 is reported to drive these diseases, implying an etiological pathogenic rational for the association between T2D and the concerned comorbidities [169].

\section{Type 2 diabetes - Implications}

mTORC1-centric view of T2D mTORC1 plays an important role in modulating and regulating metabolism across life cycle stages. Active mTORC1 is obligatory in controlling growth and development during the early age of organ development [97]. Hence, blocking its activity or maintaining its constitutive activity during the early age may result in pathology and disease. However, genetic, epigenetic or environmental conditions that maintain $\mathrm{mTORC} 1$ at that level of activity later in life may contribute to the development of T2D and its comorbidities. Hence, chronic dietary carbohydrate excess of high glycemic index, resulting in concomitant activation of the glucose-induced RagA/B.GTP and the insulin-induced Rheb.GTP drivers of mTORC1, may sustain mTORC1 hyper activity, and contribute to the T2D epidemic of modern times. Also, sedentary life style that avoids metabolic stress may further contribute to hyperactive mTORC1 [107-110] and the T2D epidemic. Indeed, suppression of mTORC1 activity in adult animal models is reported to delay and alleviate diseases of ageing and to increase lifespan [170, 171].

mTORC1 controls growth and metabolism in response to nutrients, energy and redox status, and its activity may be affected by genetic and/or epigenetic and/or tissue and/or context-dependent factors. Also, primary metabolic effects due to hyperactive mTORC1 may further be modulated by downstream secondary outcomes. Hence, an mTORC1centric view of T2D conforms to the multifactorial complexity of T2D. However, this view does not exclude additional mTORC1-independent drivers that may complement hyperactive mTORC1 in phenotyping T2D and its associated comorbidities (cancer, neurodegeneration, PCOS, other).

mTORC1-centric vs Gluco-centric paradigm of T2D The glucocentric paradigm of $\mathrm{T} 2 \mathrm{D}$ has provided an important and productive research, but also has limited the appreciation of other critical features involved in the pathogenesis and pathophysiology of T2D. The focus on hyperglycemia was driven by epidemiological data and by recognizing the benefit of strict glycemic control in delaying diabetic retinopathy, nephropathy and neuropathy in T1D patients $[172,173]$. However, extrapolating the T1D lesson to T2D patients proved to be only partially justified [174] in view of the clinical reality of T2D [36]. Most importantly, the gluco-centric approach to T2D considers the non-glycemic diseases of T2D (obesity, dyslipidemia, hypertension, diabetic macrovascular disease) as 'risk factors' or secondary 'comorbidities' or 'outcomes' to be treated symptomatically (Fig. 1), rather than inherent primary aspects of T2D pathogenic context. Also, this view fails to realize the potential double-edged role of insulin in treating hyperglycemia while driving the non-glycemic diseases of T2D. The failure to recognize the exhaustive pathogenic context of T2D and the double-edged role of insulin therapy may have contributed to T2D being still an unmet need. In contrast, the mTORC1-centric paradigm considers hyperactive $\mathrm{mTORC} 1$ to be a primary driver and primary target for treatment for both, the glycemic and non-glycemic disease aspects of T2D (Fig. 6). Of note, secondary outcomes of hyperactive mTORC1, e.g., hyperglycemia, hypertension, dyslipidemia, glucolipotoxicity, oxidative stress, other, may further contribute to the T2D phenotype. Hence, the benefit 
of treating secondary outcomes is well appreciated. However, targeting secondary outcomes per se, while failing to target hyperactive mTORC1, should not be expected to disrupt the overall clinical progression of T2D.

Pre-diabetes / diabetes The pre-diabetes / diabetes paradigm of T2D maintains an inherent difference between the two stages of T2D. However, insulin resistance in the glycemic context, the non-glycemic diseases of T2D, and characteristics of beta cells failure are already evident during the pre-diabetes stage of T2D, implying a pathogenic continuum throughout the T2D disease. Hence, the pre-diabetes / diabetes paradigm of T2D does not conform to the pathogenic reality of T2D.

T2D and insulin resistance 'Insulin resistance' is considered to be a cornerstone of T2D pathogenesis. However, 'insulin resistance' may only refer to the glycemic context of T2D, whereas the non-glycemic aspects of T2D are fully responsive to insulin and driven by hyperinsulinemia. Since the nonglycemic diseases of T2D are of major role in profiling T2D morbidity and mortality, the canonical view of 'insulin resistance' misses the exhaustive pathogenic scope of T2D. In contrast, the 'mTORC1-centric' paradigm may better describe the double-face of resistance and response to insulin in the T2D context (Fig. 5). Moreover, in terms of molecular targets for treatment, 'hyper active mTORC1' may offer an explicit target for an 'all-in-one' treatment of T2D. That is in contrast to 'insulin resistance' which indicates a phenotypic feature rather than a specific molecular target.

Insulin sensitizers 'Insulin sensitizers' (e.g., metformin, glitazones) are considered to be agents that promote response to insulin. While this is correct in relating to the glycemic context, these agents suppress the effects of insulin on the non-glycemic diseases of T2D. Indeed, 'insulin sensitizers'

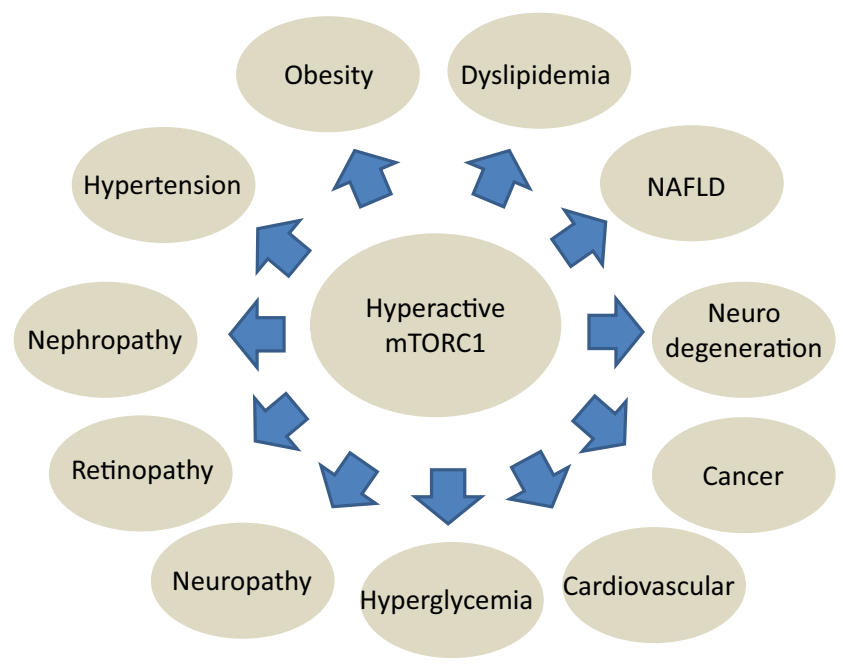

Fig. 6 mTORC1-centric paradigm of T2D. The glycemic and nonglycemic disease aspects of T2D are driven by hyperactive mTORC1 are all inhibitors of mitochondrial complex I [84, 175], resulting in suppressing mitochondrial electron flux and oxidative phosphorylation, with increase in metabolic stress and AMPK [176, 177]. Metabolic stress and AMPK inhibit mTORC1 activity (Section 3.1), thereby enhancing the glycemic effects of insulin (Section 3.3), while suppressing insulin action in driving the non-glycemic diseases of T2D (Section 3.4). Hence, the canonical view of 'insulin sensitizers' fails to realize their double-edged feature and their potential therapeutic benefit in counteracting and alleviating the non-glycemic diseases of T2D during the sub-hyperglycemic pre-diabetes stage.

Insulin(s) Insulin therapy, by either promoting its endogenous production and secretion while beta cells are still functional, or by its exogenous supply upon beta cells failure, is a corner stone of current T2D treatment. However, since insulin drives mTORC1 hyper activation, and since hyperactive mTORC1 disrupts the IR-Akt transduction pathway, insulin may serve as potent driver in promoting resistance to insulin in the glycemic context. Hence, insulin presents a double-edged agent, being required for controlling hyperglycemia while concomitantly promoting resistance to insulin in the glycemic context [178]. Indeed, insulinoma patients are resistant to insulin and recover to normal sensitivity upon tumor resection [179]. In line with that, the percentage of T2D patients who reach an $\mathrm{HbA} 1 \mathrm{C}$ target $<7.0 \%$ progressively decrease with advancing anti-diabetic treatments, amounting to $88 \%$ and $36 \%$ in patients treated with metformin only or with a variety of antidiabetic drugs including insulin, respectively [27]. Moreover, chronic insulin treatment may drive the non-glycemic diseases of T2D due to mTORC1 hyper activation via the IR-Erk/RSK transduction pathway. The apparent improvement of beta cells function by short-term intensive insulin treatment in early T2D patients [180] may delay, but not prevent, the progressive beta cells failure driven by chronic insulin treatment and hyperactive $\mathrm{mTORC1}$ [131]. In light of the major role played by the non-glycemic diseases of T2D in profiling T2D morbidity and mortality as well as in promoting T2D comorbidities (e.g., cancer, neurodegeneration, other), chronic insulin doses should be carefully considered beyond its risk of hypoglycemia. In line with that, non-insulin therapies (e.g. metformin, SGLT2i) that may reduce reliance on insulin as a mainstay for treatment should be prioritized.

Prospective treatment approaches Suppression of hyperactive mTORC1 may offer an all-in-one treatment for T2D in terms of pathogenesis, clinical focus and treatment strategy. Indeed, suppression of hyperactive mTORC1 may allow for the IR-Akt pathway to become responsive to insulin while avoiding the non-glycemic diseases of T2D. Suppression of hyperactive mTORC1 may further be expected to result in beta cells rest and preserving their function. mTORC1 may 
be targeted by caloric restriction or by carbohydrate restriction, resulting in suppressing the Rheb.GTP and RagA/B.GTP drivers of mTORC1. Ketogenic diets may indeed offer carbohydrate restriction, but at the expense of activating mTORC1 by dietary amino acids [181]. However, the compliance to caloric restriction and/or carbohydrate restriction and/or ketogenic diets is poor. Also, caloric restriction induced by bariatric surgery has limited relevance for the expanding T2D population. Treatment of T2D patients with rapalogs is dubious in light of their side effects [182], and since chronic treatment may result in inhibition of mTORC2, thereby suppressing the IR-Akt transduction pathway. The long-term success of intermittent treatment with rapalogs [183] still remains to be fully evaluated. Of note, the recently reported partial efficacy of GLP1 analogs and SGLT2i in alleviating the macrovascular disease of T2D may putatively be ascribed to their suppression of mTORC1 hyperactivity due to negative energy balance (GLP1 [184]) or urinary excretion of glucose calories (SGLT2i [185]), rather than their mild hypoglycemic efficacy. The mitochondrial complex I / mTORC1 connection exemplified by metformin $[175,186]$ may prompt a search for novel complex I inhibitors designed to suppress mTORC1 specifically.

Acknowledgments I would like to thank Terry Unterman (University of Illinois, Chicago) and Ben Glaser (Hebrew University Medical School) for their constructive comments.

Open Access This article is licensed under a Creative Commons Attribution 4.0 International License, which permits use, sharing, adaptation, distribution and reproduction in any medium or format, as long as you give appropriate credit to the original author(s) and the source, provide a link to the Creative Commons licence, and indicate if changes were made. The images or other third party material in this article are included in the article's Creative Commons licence, unless indicated otherwise in a credit line to the material. If material is not included in the article's Creative Commons licence and your intended use is not permitted by statutory regulation or exceeds the permitted use, you will need to obtain permission directly from the copyright holder. To view a copy of this licence, visit http://creativecommons.org/licenses/by/4.0/.

\section{References}

1. Standards of Medical Care in Diabetes. Diabetes Care. 2019;42(Suppl. 1):S1-2. https://doi.org/10.2337/dc19-SINT01.

2. IDF Diabetes Atlas - 8th edition. https://www.diabetesatlas.org/

3. Hostalek U. Global epidemiology of prediabetes - present and future perspectives. Clin Diabetes Endocrinol. 2019;5:5.

4. Daousi C, Casson IF, Gill GV, IA MF, Wilding JP, Pinkney JH. Prevalence of obesity in type 2 diabetes in secondary care: association with cardiovascular risk factors. Postgrad Med J. 2006;82: $280-4$.

5. Pappachan JM, Fernandez CJ, Chacko EC. Diabesity and antidiabetic drugs. Mol Asp Med. 2019;66:3-12.

6. Jacobs MJ, Kleisli T, Pio JR, Malik S, L'Italien GJ, Chen RS, et al. Prevalence and control of dyslipidemia among persons with diabetes in the United States. Diabetes Res Clin Pract. 2005;70:263-9.
7. Narindrarangkura P, Bosl W, Rangsin R, Hatthachote P. Prevalence of dyslipidemia associated with complications in diabetic patients: a nationwide study in Thailand. Lipids Health Dis. 2019;18:90.

8. Li Y, Zhao L, Yu D, Ding G. The prevalence and risk factors of dyslipidemia in different diabetic progression stages among middle-aged and elderly populations in China. PLoS One. 2018;13:e0205709.

9. Kabakov E, Norymberg C, Osher E, Koffler M, Tordjman K, Greenman Y, et al. Prevalence of hypertension in type 2 diabetes mellitus: impact of the tightening definition of high blood pressure and association with confounding risk factors. J Cardiometab Syndr. 2006;1:95-101.

10. Dai W, Ye L, Liu A, Wen SW, Deng J, Wu X, et al. Prevalence of nonalcoholic fatty liver disease in patients with type 2 diabetes mellitus: a meta-analysis. Medicine (Baltimore). 2017;96:e8179.

11. Zhang J, Chen C, Hua S, Liao H, Wang M, Xiong Y, et al. An updated meta-analysis of cohort studies: diabetes and risk of Alzheimer's disease. Diabetes Res Clin Pract. 2017;124:41-7.

12. Habib SL, Rojna M. Diabetes and risk of cancer. ISRN Oncol. 2013;2013:583786.

13. Einarson TR, Acs A, Ludwig C, Panton UH. Prevalence of cardiovascular disease in type 2 diabetes: a systematic literature review of scientific evidence from across the world in 2007-2017. Cardiovasc Diabetol. 2018;17:83.

14. Gheith O, Farouk N, Nampoory N, Halim MA, Al-Otaibi T. Diabetic kidney disease: world wide difference of prevalence and risk factors. J Nephropharmacol. 2015;5:49-56 eCollection 2016.

15. Ruta LM, Magliano DJ, Lemesurier R, Taylor HR, Zimmet $\mathrm{PZ}$, Shaw JE. Prevalence of diabetic retinopathy in type 2 diabetes in developing and developed countries. Diabet Med. 2013;30:387-98.

16. Juster-Switlyk K, Smith AG. Updates in diabetic peripheral neuropathy. F1000Res. 2016;5:F1000 Faculty Rev-738.

17. Alberti KG, Eckel RH, Grundy SM, Zimmet PZ, Cleeman JI, Donato KA, et al. Circulation. 2009;120:1640-5.

18. Barr EL, Zimmet PZ, Welborn TA, Jolley D, Magliano DJ, Dunstan DW, et al. Risk of cardiovascular and all-cause mortality in individuals with diabetes mellitus, impaired fasting glucose, and impaired glucose tolerance: the Australian diabetes, obesity, and lifestyle study (AusDiab). Circulation. 2007;11:151-7.

19. Huang Y, Cai X, Mai W, Li M, Hu Y. Association between prediabetes and risk of cardiovascular disease and all cause mortality: systematic review and meta-analysis. BMJ. 2016;355:i5953.

20. Plantinga LC, Crews DC, Coresh J, Miller ER 3rd, Saran R, Yee J, et al. CDC CKD surveillance team. Prevalence of chronic kidney disease in US adults with undiagnosed diabetes or prediabetes. Clin J Am Soc Nephrol. 2010;5:673-82.

21. Sumner CJ, Sheth S, Griffin JW, Cornblath DR, Polydefkis M. The spectrum of neuropathy in diabetes and impaired glucose tolerance. Neurology. 2003;6:108-11.

22. Cortez M, Singleton JR, Smith AG. Glucose intolerance, metabolic syndrome, and neuropathy. Handb Clin Neurol. 2014;126: 109-22.

23. Diabetes Prevention Program Research Group. The prevalence of retinopathy in impaired glucose tolerance and recent-onset diabetes in the diabetes prevention program. Diabet Med. 2007;24:137-44.

24. Huang Y, Cai X, Mai W, Li M, Hu Y. Association between prediabetes and risk of cardiovascular disease and all cause mortality: systematic review and meta-analysis. BMJ. 2016;355:15953.

25. Diabetes Mellitus - Evaluating Cardiovascular Risk in New Antidiabetic Therapies to Treat Type 2 Diabetes. FDA 2008. https://www.fda.gov/media/71297/download 
26. Bommer C, Sagalova V, Heesemann E, Manne-Goehler J, Atun R, Bärnighausen $\mathrm{T}$, et al. Global economic burden of diabetes in adults: projections from 2015 to 2030. Diabetes Care. 2018;41: 963-70.

27. de Pablos-Velasco P, Parhofer KG, Bradley C, Eschwège E, Gönder-Frederick L, Maheux P, et al. Current level of glycemic control and its associated factors in patients with type 2 diabetes across Europe: data from the PANORAMA study. Clin Endocrinol. 2014;80:47-56.

28. Ali MK, Bullard KM, Saaddine JB, Cowie CC, Imperatore G, Gregg EW. Achievement of goals in U.S. diabetes care, 19992010. N Engl J Med. 2013;368:1613-24.

29. Kazemian P, Shebl FM, McCann N, Walensky RP, Wexler DJ. Evaluation of the Cascade of Diabetes Care in the United States, 2005-2016. JAMA Intern Med. 2019;179:1376-85.

30. Zoungas S, Chalmers J, Ninomiya T, Li Q, Cooper ME, Colagiuri $\mathrm{S}$, et al. Association of $\mathrm{HbA} 1 \mathrm{c}$ levels with vascular complications and death in patients with type 2 diabetes: evidence of glycaemic thresholds. Diabetologia. 2012;55:636-43.

31. Action to Control Cardiovascular Risk in Diabetes Study Group, Gerstein HC, Miller ME, Byington RP, Goff DC Jr, Bigger JT, et al. Effects of intensive glucose lowering in type 2 diabetes. $\mathrm{N}$ Engl J Med. 2008;358:2545-59.

32. ADVANCE Collaborative Group, Patel A, MacMahon S, Chalmers J, Neal B, Billot L, et al. Intensive blood glucose control and vascular outcomes in patients with type 2 diabetes. N Engl $\mathrm{J}$ Med. 2008;358:2560-72.

33. Duckworth W, Abraira C, Moritz T, Reda D, Emanuele N, Reaven $\mathrm{PD}$, et al. Huang GD; VADT investigators. Glucose control and vascular complications in veterans with type 2 diabetes. $\mathrm{N}$ Engl $\mathrm{J}$ Med. 2009;360:129-39.

34. Reaven PD, Emanuele NV, Wiitala WL, Bahn GD, Reda DJ, McCarren M, et al. Intensive glucose control in patients with type 2 diabetes - 15-year follow-up. N Engl J Med. 2019;380:2215-24.

35. MacIsaac RJ, Jerums G, Ekinci EI. Effects of glycaemic management on diabetic kidney disease. World J Diabetes. 2017;8: 172-86.

36. Papademetriou V, Lovato L, Doumas M, Nylen E, Mottl A, Cohen RM, et al. Chronic kidney disease and intensive glycemic control increase cardiovascular risk in patients with type 2 diabetes. Kidney Int. 2015;87:649-59.

37. Marso SP, Daniels GH, Brown-Frandsen K, Kristensen P, Mann JF, Nauck MA, et al. Liraglutide and cardiovascular outcomes in type 2 diabetes. N Engl J Med. 2016;375:311-22.

38. Zinman B, Wanner C, Lachin JM, Fitchett D, Bluhmki E, Hantel $\mathrm{S}$, et al. Empagliflozin, cardiovascular outcomes, and mortality in type 2 diabetes. N Engl J Med. 2015;373:2117-28.

39. Neal B, Perkovic V, Mahaffey KW, de Zeeuw D, Fulcher G, Erondu N, et al. Matthews DR; CANVAS program collaborative group. Canagliflozin and cardiovascular and renal events in type 2 diabetes. N Engl J Med. 2017;377:644-57.

40. Das SR, Everett BM, Birtcher KK, Brown JM, Cefalu WT, Januzzi JL Jr, et al. ACC expert consensus decision pathway on novel therapies for cardiovascular risk reduction in patients with type 2 diabetes and atherosclerotic cardiovascular disease: a report of the American College of Cardiology Task Force on expert consensus decision pathways. J Am Coll Cardiol. 2018;72: 3200-23.

41. Knowler WC, Barrett-Connor E, Fowler SE, Hamman RF, Lachin JM, Walker EA, et al. Diabetes prevention program research group. Reduction in the incidence of type 2 diabetes with lifestyle intervention or metformin. N Engl J Med. 2002;346:393-403.

42. Look AHEAD Research Group, Wing RR, Bolin P, Brancati FL, Bray GA, Clark JM, et al. Cardiovascular effects of intensive lifestyle intervention in type 2 diabetes. $\mathrm{N}$ Engl $\mathrm{J}$ Med. 2013;369:145-54.
43. Cui JY, Zhou RR, Han S, Wang TS, Wang LQ, Xie XH. Statin therapy on glycemic control in type 2 diabetic patients: a network meta-analysis. J Clin Pharm Ther. 2018;43:556-70.

44. Zhang X, Zhao Q. Association of Thiazide-Type Diuretics with Glycemic Changes in hypertensive patients: a systematic review and meta-analysis of randomized controlled clinical trials. J Clin Hypertens (Greenwich). 2016;18:342-51.

45. Bangalore S, Parkar S, Grossman E, Messerli FH. A meta-analysis of 94,492 patients with hypertension treated with beta blockers to determine the risk of new-onset diabetes mellitus. Am J Cardiol. 2007;100:1254-62.

46. Cersosimo E, Triplitt C, Solis-Herrera C, Mandarino LJ, DeFronzo RA. Pathogenesis of Type 2 Diabetes Mellitus. 2018. In: Feingold KR, Anawalt B, Boyce A, Chrousos G, Dungan K, Grossman A, Hershman JM, Kaltsas G, Koch C, Kopp P, Korbonits M, McLachlan R, Morley JE, New M, Perreault L, Purnell J, Rebar R, Singer F, Trence DL, Vinik A, Wilson DP, editors.

47. Tabák AG, Herder C, Rathmann W, Brunner EJ, Kivimäki M. Prediabetes: a high-risk state for diabetes development. Lancet. 2012;379:2279-90.

48. DeFronzo RA, Tripathy D. Skeletal muscle insulin resistance is the primary defect in type 2 diabetes. Diabetes Care. 2009;32(Suppl 2):S157-63.

49. Warram JH, Martin BC, Krolewski AS, Soeldner JS, Kahn CR. Slow glucose removal rate and hyperinsulinemia precede the development of type II diabetes in the offspring of diabetic parents. Ann Intern Med. 1990;113:909-15.

50. Czech MP. Insulin action and resistance in obesity and type 2 diabetes. Nat Med. 2017;23:804-14.

51. Del Prato S, Leonetti F, Simonson DC, Sheehan P, Matsuda M, De Fronzo RA. Effect of sustained physiologic hyperinsulinaemia and hyperglycaemia on insulin secretion and insulin sensitivity in man. Diabetologia. 1994;37:1025-35.

52. Iozzo P, Pratipanawatr T, Pijl H, Vogt C, Kumar V, Pipek R, et al. Physiological hyperinsulinemia impairs insulin-stimulated glycogen synthase activity and glycogen synthesis. Am J Physiol Endocrinol Metab. 2001;280:E712-9.

53. Kahn CR. Insulin resistance, insulin insensitivity, and insulin unresponsiveness: a necessary distinction. Metabolism. 1978;27: 1893-902.

54. Kolterman OG, Gray RS, Griffin J, Burstein P, Insel J, Scarlett JA, et al. Receptor and postreceptor defects contribute to the insulin resistance in noninsulin-dependent diabetes mellitus. J Clin Invest. 1981;68:957-69.

55. Caro JF, Sinha MK, Raju SM, Ittoop O, Pories WJ, Flickinger EG, et al. Insulin receptor kinase in human skeletal muscle from obese subjects with and without noninsulin dependent diabetes. J Clin Invest. 1987;79:1330-7.

56. Huang X, Liu G, Guo J, Su Z. The PI3K/AKT pathway in obesity and type 2 diabetes. Int J Biol Sci. 2018;14:1483-96.

57. Brown MS, Goldstein JL. Selective versus total insulin resistance: a pathogenic paradox. Cell Metab. 2008;7:95-6.

58. Sparks JD, Sparks CE, Adeli K. Selective hepatic insulin resistance, VLDL overproduction, and hypertriglyceridemia. Arterioscler Thromb Vasc Biol. 2012;32:2104-12.

59. Semple RK, Sleigh A, Murgatroyd PR, Adams CA, Bluck L, Jackson S, et al. Postreceptor insulin resistance contributes to human dyslipidemia and hepatic steatosis. J Clin Invest. 2009;119: 315-22.

60. Han S, Liang CP, Westerterp M, Senokuchi T, Welch CL, Wang Q, et al. Hepatic insulin signaling regulates VLDL secretion and atherogenesis in mice. J Clin Invest. 2009;119:1029-41.

61. Vatner DF, Majumdar SK, Kumashiro N, Petersen MC, Rahimi Y, Gattu AK, et al. Insulin-independent regulation of hepatic 
triglyceride synthesis by fatty acids. Proc Natl Acad Sci U S A. 2015;112:1143-8.

62. Petersen MC, Shulman GI. Mechanisms of insulin action and insulin resistance. Physiol Rev. 2018;98:2133-223.

63. Titchenell PM, Quinn WJ, Lu M, Chu Q, Lu W, Li C, et al. Direct hepatocyte insulin signaling is required for lipogenesis but is dispensable for the suppression of glucose production. Cell Metab. 2016;23:1154-66.

64. Titchenell PM, Lazar MA, Birnbaum MJ. Unraveling the regulation of hepatic metabolism by insulin. Trends Endocrinol Metab. 2017;28:497-505.

65. Santoleri D, Titchenell PM. Resolving the paradox of hepatic insulin resistance. Cell Mol Gastroenterol Hepatol. 2019;7:447-56.

66. Cook JR, Langlet F, Kido Y, Accili D. Pathogenesis of selective insulin resistance in isolated hepatocytes. J Biol Chem. 2015;290: 13972-80.

67. Kubota N, Kubota T, Kajiwara E, Iwamura T, Kumagai H, Watanabe T, et al. Differential hepatic distribution of insulin receptor substrates causes selective insulin resistance in diabetes and obesity. Nat Commun. 2016;7:12977.

68. Alemzadeh R, Langley G, Upchurch L, Smith P, Slonim AE. Beneficial effect of diazoxide in obese hyperinsulinemic adults. J Clin Endocrinol Metab. 1998;83:1911-5.

69. Kolb H, Stumvoll M, Kramer W, Kempf K, Martin S. Insulin translates unfavourable lifestyle into obesity. BMC Med. 2018; 16:232

70. Page MM, Johnson JD. Mild suppression of hyperinsulinemia to treat obesity and insulin resistance. Trends Endocrinol Metab. 2018;29:389-99.

71. Lim K, Jackson KL, Sata Y, Head GA. Factors responsible for obesity-related hypertension. Curr Hypertens Rep. 2017;19:53.

72. Thorp AA, Schlaich MP. Relevance of sympathetic nervous system activation in obesity and metabolic syndrome. J Diabetes Res. 2015;2015:341583.

73. Brands MW, Manhiani MM. Sodium-retaining effect of insulin in diabetes. Am J Physiol Regul Integr Comp Physiol. 2012;303: R1101-9.

74. Muniyappa R, Sowers JR. Role of insulin resistance in endothelial dysfunction. Rev Endocr Metab Disord. 2013;14:5-12.

75. Toyoki D, Shibata S, Kuribayashi-Okuma E, Xu N, Ishizawa K, Hosoyamada M, et al. Insulin stimulates uric acid reabsorption via regulating urate transporter 1 and ATP-binding cassette subfamily G member 2. Am J Physiol Renal Physiol. 2017;313:F826-34.

76. Shimizu I, Minamino T, Toko H, Okada S, Ikeda H, Yasuda N, et al. Excessive cardiac insulin signaling exacerbates systolic dysfunction induced by pressure overload in rodents. J Clin Invest. 2010;120:1506-14.

77. Hsueh WA, Law RE. Insulin signaling in the arterial wall. Am J Cardiol. 1999;84:21J-4J.

78. Gonzalez-Franquesa A, Patti ME. Insulin resistance and mitochondrial dysfunction. Adv Exp Med Biol. 2017;982:465-520.

79. Pinti MV, Fink GK, Hathaway QA, Durr AJ, Kunovac A, Hollander JM. Mitochondrial dysfunction in type 2 diabetes mellitus: an organ-based analysis. Am J Physiol Endocrinol Metab. 2019;316:E268-85.

80. McGarry JD. What if Minkowski had been ageusic? An alternative angle on diabetes. Science. 1992;258:766-70.

81. Lockman KA, Nyirenda MJ. Interrelationships between hepatic fat and insulin resistance in non-alcoholic fatty liver disease. Curr Diabetes Rev. 2010;6:341-7.

82. An J, Muoio DM, Shiota M, Fujimoto Y, Cline GW, Shulman GI, et al. Hepatic expression of malonyl-CoA decarboxylase reverses muscle, liver and whole-animal insulin resistance. Nat Med. 2004; 10:268-74.

83. Li X, Li Z, Zhao M, Nie Y, Liu P, Zhu Y, et al. Skeletal muscle lipid droplets and the Athlete's paradox. Cells. 2019;8:E249.
84. Zhang Y, Ye J. Mitochondrial inhibitor as a new class of insulin sensitizer. Acta Pharm Sin B. 2012;2:341-9.

85. Holloszy JO. "deficiency" of mitochondria in muscle does not cause insulin resistance. Diabetes. 2013;62:1036-40.

86. Loh K, Deng H, Fukushima A, Cai X, Boivin B, Galic S, et al. Reactive oxygen species enhance insulin sensitivity. Cell Metab. 2009; 10:260-72.

87. Lee HY, Lee JS, Alves T, Ladiges W, Rabinovitch PS, Jurczak MJ, et al. Mitochondrial-targeted catalase protects against high-fat diet-induced muscle insulin resistance by decreasing intramuscular lipid accumulation. Diabetes. 2017;66:2072-81.

88. Martin SD, Morrison S, Konstantopoulos N, McGee SL. Mitochondrial dysfunction has divergent, cell type-dependent effects on insulin action. Mol Metab. 2014;3:408-18.

89. Lei XG, Zhu JH, Cheng WH, Bao Y, Ho YS, Reddi AR, et al. Aradoxical roles of antioxidant enzymes: basic mechanisms and health implications. Physiol Rev. 2016;96:307-64.

90. Costes S, Langen R, Gurlo T, Matveyenko AV, Butler PC. $\beta$-Cell failure in type 2 diabetes: a case of asking too much of too few? Diabetes. 2013;62:327-35.

91. Ferrannini E. The stunned beta cell: a brief history. Cell Metab. 2010;11:349-52.

92. Prentki M, Nolan CJ. Islet beta cell failure in type 2 diabetes. J Clin Invest. 2006;116:1802-12.

93. Halban PA, Polonsky KS, Bowden DW, Hawkins MA, Ling C, Mather KJ, et al. $\beta$-Cell failure in type 2 diabetes: postulated mechanisms and prospects for prevention and treatment. Diabetes Care. 2014;37:1751-8.

94. Leibowitz G, Kaiser N, Cerasi E. $\beta$-Cell failure in type 2 diabetes. J Diabetes Investig. 2011;2:82-91.

95. Butler AE, Janson J, Bonner-Weir S, Ritzel R, Rizza RA, Butler PC. Beta-cell deficit and increased beta-cell apoptosis in humans with type 2 diabetes. Diabetes. 2003;52:102-10.

96. Prospective Diabetes Study Group. U.K. prospective diabetes study 16 . Overview of 6 years' therapy of type II diabetes: a progressive disease. U.K. Diabetes. 1995;44:1249-58.

97. Saxton RA, Sabatini DM. mTOR signaling in growth, metabolism, and disease. Cell. 2017;168:960-76.

98. Blagosklonny MV. TOR-centric view on insulin resistance and diabetic complications: perspective for endocrinologists and gerontologists. Cell Death Dis. 2013;4:e964.

99. Boutouja F, Stiehm CM, Platta HW. mTOR: a cellular regulator Interface in health and disease. Cells. 2019;8:E18.

100. Efeyan A, Zoncu R, Chang S, Gumper I, Snitkin H, Wolfson RL, et al. Regulation of mTORC1 by the rag GTPases is necessary for neonatal autophagy and survival. Nature. 2013;493:679-83.

101. Zhang CS, Jiang B, Li M, Zhu M, Peng Y, Zhang YL, et al. The lysosomal v-ATPase-Ragulator complex is a common activator for AMPK and mTORC1, acting as a switch between catabolism and anabolism. Cell Metab. 2014;20:526-40.

102. Zhang CS, Hawley SA, Zong Y, Li M, Wang Z, Gray A, et al. Fructose-1,6-bisphosphate and aldolase mediate glucose sensing by AMPK. Nature. 2017;548:112-6.

103. Manning BD, Tee AR, Logsdon MN, Blenis J, Cantley LC. Identification of the tuberous sclerosis complex-2 tumor suppressor gene product tuberin as a target of the phosphoinositide 3kinase/akt pathway. Mol Cell. 2002;10:151-62.

104. Kovacina KS, Park GY, Bae SS, Guzzetta AW, Schaefer E, Birnbaum MJ, et al. Identification of a proline-rich Akt substrate as a 14-3-3 binding partner. J Biol Chem. 2003;278:10189-94.

105. Roux PP, Ballif BA, Anjum R, Gygi SP, Blenis J. Tumorpromoting phorbol esters and activated Ras inactivate the tuberous sclerosis tumor suppressor complex via p90 ribosomal S6 kinase. Proc Natl Acad Sci U S A. 2004;101:13489-94. 
106. Lee DF, Kuo HP, Chen CT, Hsu JM, Chou CK, Wei Y, et al. IKK beta suppression of TSC1 links inflammation and tumor angiogenesis via the mTOR pathway. Cell. 2007;130(3):440-55.

107. Inoki K, Zhu T, Guan KL. TSC2 mediates cellular energy response to control cell growth and survival. Cell. 2003;115:577-90.

108. Gwinn DM, Shackelford DB, Egan DF, Mihaylova MM, Mery A, Vasquez DS, et al. AMPK phosphorylation of raptor mediates a metabolic checkpoint. Mol Cell. 2008;30:214-26.

109. Demetriades C, Plescher M, Teleman AA. Lysosomal recruitment of TSC2 is a universal response to cellular stress. Nat Commun. 2016;7:10662.

110. Sofer A, Lei K, Johannessen CM, Ellisen LW. Regulation of mTOR and cell growth in response to energy stress by REDD1. Mol Cell Biol. 2005;25:5834-45.

111. Schreiber KH, Ortiz D, Academia EC, Anies AC, Liao CY, Kennedy BK. Rapamycin-mediated mTORC2 inhibition is determined by the relative expression of FK506-binding proteins. Aging Cell. 2015;14:265-73.

112. Choo AY, Yoon SO, Kim SG, Roux PP, Blenis J. Rapamycin differentially inhibits S6Ks and 4E-BP1 to mediate cell-typespecific repression of mRNA translation. Proc Natl Acad Sci U S A. 2008;105:17414-9.

113. Tzatsos A, Kandror KV. Nutrients suppress phosphatidylinositol 3-kinase/Akt signaling via raptor-dependent mTOR-mediated insulin receptor substrate 1 phosphorylation. Mol Cell Biol. 2006;26:63-76.

114. Copps KD, White MF. Regulation of insulin sensitivity by serine/ threonine phosphorylation of insulin receptor substrate proteins IRS1 and IRS2. Diabetologia. 2012;55:2565-82.

115. Yoneyama Y, Inamitsu T, Chida K, Iemura SI, Natsume T, Maeda $\mathrm{T}$, et al. Serine phosphorylation by mTORC1 promotes IRS-1 degradation through SCF $\beta$-TRCP E3 ubiquitin ligase. Science. 2018;5:1-18.

116. Hsu PP, Kang SA, Rameseder J, Zhang Y, Ottina KA, Lim D, et al. The mTOR-regulated phosphoproteome reveals a mechanism of mTORC1-mediated inhibition of growth factor signaling. Science. 2011;332:1317-22.

117. Yu Y, Yoon SO, Poulogiannis G, Yang Q, Ma XM, Villén J, et al. Phosphoproteomic analysis identifies Grb10 as an mTORC1 substrate that negatively regulates insulin signaling. Science. 2011;332:1322-6.

118. Liu P, Gan W, Inuzuka H, Lazorchak AS, Gao D, Arojo O, et al. Sin 1 phosphorylation impairs mTORC2 complex integrity and inhibits downstream Akt signalling to suppress tumorigenesis. Nat Cell Biol. 2013;15:1340-50.

119. Julien LA, Carriere A, Moreau J, Roux PP. mTORC1-activated S6K1 phosphorylates Rictor on threonine 1135 and regulates mTORC2 signaling. Mol Cell Biol. 2010;30:908-21.

120. Um SH, Frigerio F, Watanabe M, Picard F, Joaquin M, Sticker M, et al. Absence of S6K1 protects against age- and diet-induced obesity while enhancing insulin sensitivity. Nature. 2004;431: 200-5.

121. Bae EJ, Xu J, Oh DY, Bandyopadhyay G, Lagakos WS, Keshwani $\mathrm{M}$, et al. Liver-specific p70 S6 kinase depletion protects against hepatic steatosis and systemic insulin resistance. J Biol Chem. 2012;287:18769-80.

122. Cusi K, Maezono K, Osman A, Pendergrass M, Patti ME, Pratipanawatr $\mathrm{T}$, et al. Insulin resistance differentially affects the PI 3-kinase- and MAP kinase-mediated signaling in human muscle. J Clin Invest. 2000;105:311-20.

123. Ueyama A, Ban N, Fukazawa M, Hirayama T, Takeda M, Yata T, et al. Inhibition of MEK1 signaling pathway in the liver ameliorates insulin resistance. J Diabetes Res. 2016;2016:8264830.

124. Zimmermann S, Moelling K. Phosphorylation and regulation of Raf by Akt (protein kinase B). Science. 1999;286:1741-4.
125. Mendoza MC, Er EE, Blenis J. The Ras-ERK and PI3K-mTOR pathways: cross-talk and compensation. Trends Biochem Sci. 2011;36:320-8.

126. Malakar P, Chartarifsky L, Hija A, Leibowitz G, Glaser B, Dor Y, et al. Insulin receptor alternative splicing is regulated by insulin signaling and modulates beta cell survival. Sci Rep. 2016;6: 31222.

127. Sidarala V, Kowluru A. The regulatory roles of mitogen-activated protein kinase (MAPK) pathways in health and diabetes: lessons learned from the pancreatic $\beta$-cell. Recent Pat Endocr Metab Immune Drug Discov. 2017;10:76-84.

128. Zhao J, Goldberg AL. Coordinate regulation of autophagy and the ubiquitin proteasome system by MTOR. Autophagy. 2016;12: 1967-70.

129. Szegezdi E, Logue SE, Gorman AM, Samali A. Mediators of endoplasmic reticulum stress-induced apoptosis. EMBO Rep. 2006:7:880-5.

130. Okada T, Liew CW, Hu J, Hinault C, Michael MD, Krtzfeldt J, et al. Insulin receptors in beta-cells are critical for islet compensatory growth response to insulin resistance. Proc Natl Acad Sci U S A. 2007;104:8977-82.

131. Ardestani A, Lupse B, Kido Y, Leibowitz G, Maedler K. mTORC1 signaling: a double-edged sword in diabetic $\beta$ cells. Cell Metab. 2018;27:314-31.

132. Shigeyama Y, Kobayashi T, Kido Y, Hashimoto N, Asahara S, Matsuda T, et al. Biphasic response of pancreatic beta-cell mass to ablation of tuberous sclerosis complex 2 in mice. Mol Cell Biol. 2008;28:2971-9.

133. Kang YE, Kim JM, Joung KH, Lee JH, You BR, Choi MJ, et al. The roles of Adipokines, Proinflammatory cytokines, and adipose tissue macrophages in obesity-associated insulin resistance in modest obesity and early metabolic dysfunction. PLoS One. 2016;11:e154003.

134. Chen W, Balland E, Cowley MA. Hypothalamic insulin resistance in obesity: effects on glucose homeostasis. Neuroendocrinology. 2017;104:364-81.

135. Ono H. Molecular mechanisms of hypothalamic insulin resistance. Int J Mol Sci. 2019;20:E1317.

136. Zhang HH, Huang J, Düvel K, Boback B, Wu S, Squillace RM, et al. Insulin stimulates adipogenesis through the Akt-TSC2mTORC1 pathway. PLoS One. 2009;4:e6189.

137. Li S, Brown MS, Goldstein JL. Bifurcation of insulin signaling pathway in rat liver: mTORC1 required for stimulation of lipogenesis, but not inhibition of gluconeogenesis. Proc Natl Acad Sci U S A. 2010;107:3441-6.

138. Han J, Li E, Chen L, Zhang Y, Wei F, Liu J, et al. The CREB coactivator CRTC2 controls hepatic lipid metabolism by regulating SREBP1. Nature. 2015;524:243-6.

139. Chakrabarti P, English T, Shi J, Smas CM, Kandror KV. Mammalian target of rapamycin complex 1 suppresses lipolysis, stimulates lipogenesis, and promotes fat storage. Diabetes. 2010;59:775-81.

140. Sengupta S, Peterson TR, Laplante M, Oh S, Sabatini DM. mTORC1 controls fasting-induced ketogenesis and its modulation by ageing. Nature. 2010;468:1100-4.

141. Hirano T. Pathophysiology of diabetic dyslipidemia. J Atheroscler Thromb. 2018;25:771-82.

142. JQuinn WJ 3rd, Wan M, Shewale SV, Gelfer R, Rader DJ, Birnbaum MJ, et al. mTORC1 stimulates phosphatidylcholine synthesis to promote triglyceride secretion. Clin Invest. 2017:127:4207-15.

143. Kamagate A, Qu S, Perdomo G, Su D, Kim DH, Slusher S, et al. FoxO1 mediates insulin-dependent regulation of hepatic VLDL production in mice. J Clin Invest. 2008;118:2347-64. 
144. Altomonte J, Cong L, Harbaran S, Richter A, Xu J, Meseck M, et al. Foxo1 mediates insulin action on apoC-III and triglyceride metabolism. J Clin Invest. 2004;114:1493-503.

145. Ferrannini E, Buzzigoli G, Bonadonna R, Giorico MA, Oleggini $\mathrm{M}$, Graziadei L, et al. Insulin resistance in essential hypertension. N Engl J Med. 1987;317:350-7.

146. Horita S, Seki G, Yamada H, Suzuki M, Koike K, Fujita T. Insulin resistance, obesity, hypertension, and renal sodium transport. Int J Hypertens. 2011;2011:391762.

147. Feraille E, Dizin E. Coordinated control of ENaC and $\mathrm{Na}+, \mathrm{K}+-$ ATPase in renal collecting duct. J Am Soc Nephrol. 2016;27: 2554-63.

148. Michlig S, Mercier A, Doucet A, Schild L, Horisberger JD, Rossier BC, et al. ERK1/2 controls Na,K-ATPase activity and transepithelial sodium transport in the principal cell of the cortical collecting duct of the mouse kidney. J Biol Chem. 2004;279: 51002-12.

149. Féraille E, Rousselot M, Rajerison R, Favre H. Effect of insulin on $\mathrm{Na}+, \mathrm{K}(+)-A T P a s e$ in rat collecting duct. J Physiol. 1995;488: 171-80.

150. Pesce L, Guerrero C, Comellas A, Ridge KM, Sznajder JI. Betaagonists regulate $\mathrm{Na}, \mathrm{K}-\mathrm{ATPase}$ via novel MAPK/ERK and rapamycin-sensitive pathways. FEBS Lett. 2000;486:310-4.

151. Harlan SM, Guo DF, Morgan DA, Fernandes-Santos C, Rahmouni K. Hypothalamic mTORC1 signaling controls sympathetic nerve activity and arterial pressure and mediates leptin effects. Cell Metab. 2013;17:599-606.

152. Wengrofsky P, Lee J, Makaryus AN. Dyslipidemia and its role in the pathogenesis of atherosclerotic cardiovascular disease: implications for evaluation and targets for treatment of dyslipidemia based on recent guidelines. IntechOpen 2019. https://doi.org/10. 5772/intechopen.85772.

153. Dunlay SM, Givertz MM, Aguilar D, Allen LA, Chan M, Desai AS, et al. American Heart Association heart failure and transplantation Committee of the Council on clinical cardiology; council on cardiovascular and stroke nursing; and the Heart Failure Society of America. Type 2 diabetes mellitus and heart failure: a scientific statement from the American Heart Association and the Heart Failure Society of America: this statement does not represent an update of the 2017 ACC/AHA/HFSA heart failure guideline update. Circulation. 2019;140(7):e294-324.

154. Borén J, Williams KJ. The central role of arterial retention of cholesterol-rich apolipoprotein-B-containing lipoproteins in the pathogenesis of atherosclerosis: a triumph of simplicity. Curr Opin Lipidol. 2016;27:473-83.

155. King GL, Park K, Li Q. Selective insulin resistance and the development of cardiovascular diseases in diabetes: the 2015 Edwin Bierman award lecture. Diabetes. 2016;65:1462-71.

156. Jia G, Hill MA, Sowers JR. Diabetic cardiomyopathy: An update of mechanisms contributing to this clinical entity. Circ Res. 2018;122:624-38.

157. Sciarretta S, Forte M, Frati G, Sadoshima J. New insights into the role of mTOR signaling in the cardiovascular system. Circ Res. 2018;122:489-505.

158. Ising C, Koehler S, Brähler S, Merkwirth C, Höhne M, Baris OR, et al. Inhibition of insulin/IGF-1 receptor signaling protects from mitochondria-mediated kidney failure. EMBO Mol Med. 2015;7: $275-87$

159. Mori H, Inoki K, Masutani K, Wakabayashi Y, Komai K, Nakagawa R, et al. The mTOR pathway is highly activated in diabetic nephropathy and rapamycin has a strong therapeutic potential. Biochem Biophys Res Commun. 2009;384:471-5.

160. Gödel M, Hartleben B, Herbach N, Liu S, Zschiedrich S, Lu S, et al. Role of mTOR in podocyte function and diabetic nephropathy in humans and mice. J Clin Invest. 2011;121:2197-209.
161. Inoki K, Mori H, Wang J, Suzuki T, Hong S, Yoshida S, et al. mTORC1 activation in podocytes is a critical step in the development of diabetic nephropathy in mice. J Clin Invest. 2011;121: 2181-96.

162. Koral K, Erkan E. PKB/Akt partners with Dab2 in albumin endocytosis. Am J Physiol Renal Physiol. 2012;302:F1013-24.

163. Rosa MD, Distefano G, Gagliano C, Rusciano D, Malaguarnera L. Autophagy in diabetic retinopathy. Curr Neuropharmacol. 2016;14:810-25.

164. Brugarolas JB, Vazquez F, Reddy A, Sellers WR, Kaelin WG Jr. TSC2 regulates VEGF through mTOR-dependent and independent pathways. Cancer Cell. 2003;4:147-58.

165. Dodd KM, Yang J, Shen MH, Sampson JR, Tee AR. mTORC1 drives HIF- $1 \alpha$ and VEGF-A signalling via multiple mechanisms involving 4E-BP1, S6K1 and STAT3. Oncogene. 2015;34: 2239-50.

166. Lisi L, Aceto P, Navarra P, Dello RC. mTOR kinase: a possible pharmacological target in the management of chronic pain. Biomed Res Int. 2015;2015:394257.

167. Lutz BM, Nia S, Xiong M, Tao YX, Bekker A. mTOR, a new potential target for chronic pain and opioid-induced tolerance and hyperalgesia. Mol Pain. 2015;11:32.

168. Wu LY, Li M, Qu ML, Li X, Pi LH, Chen Z, et al. High glucose up-regulates Semaphorin $3 \mathrm{~A}$ expression via the mTOR signaling pathway in keratinocytes: a potential mechanism and therapeutic target for diabetic small fiber neuropathy. Mol Cell Endocrinol. 2018;472:107-16.

169. El Hiani Y, Egom EE, Dong XP. mTOR signalling: jack-of-alltrades. Biochem Cell Biol. 2019;97:58-67.

170. Papadopoli D, Boulay K, Kazak L, Pollak M, Mallette F, Topisirovic I, et al. mTOR as a central regulator of lifespan and aging. F1000Res. 2019;8:F1000 Faculty Rev-998.

171. Weichhart T. mTOR as regulator of lifespan, aging, and cellular senescence: a mini-review. Gerontology. 2018;64:127-34.

172. The Diabetes Control and Complications Trial Research Group. The effect of intensive therapy of diabetes on the development and progression of long-term complications in insulin-dependent diabetes mellitus. N Engl J Med. 1993;329:977-86.

173. Diabetes Control and Complications Trial/Epidemiology of Diabetes Interventions and Complications Research Group. Retinopathy and nephropathy in patients with type 1 diabetes four years after a trial of intensive therapy. N Engl J Med. 2000;342(6): 381-9.

174. UK Prospective Diabetes Study (UKPDS) Group. Intensive blood-glucose control with sulphonylureas or insulin compared with conventional treatment and risk of complications in patients with type 2 diabetes (UKPDS 33). Lancet. 1998;352:837-53.

175. Wheaton WW, Weinberg SE, Hamanaka RB, Soberanes S, Sullivan LB, Anso E, et al. Metformin inhibits mitochondrial complex I of cancer cells to reduce tumorigenesis. Elife. 2014;3: $\mathrm{e} 02242$.

176. Hardie DG, Lin SC. AMP-activated protein kinase - not just an energy sensor. F1000Res. 2017;6:1724.

177. Lin SC, Hardie DG. AMPK: sensing glucose as well as cellular energy status. Cell Metab. 2018;27:299-313.

178. Liu HY, Cao SY, Hong T, Han J, Liu Z, Cao W. Insulin is a stronger inducer of insulin resistance than hyperglycemia in mice with type 1 diabetes mellitus (T1DM). J Biol Chem. 2009;284: 27090-100.

179. Furnica RM, Istasse L, Maiter D. A severe but reversible reduction in insulin sensitivity is observed in patients with insulinoma. Ann Endocrinol (Paris). 2018;79:30-6.

180. Chen HS, Wu TE, Jap TS, Hsiao LC, Lee SH, Lin HD. Beneficial effects of insulin on glycemic control and beta-cell function in newly diagnosed type 2 diabetes with severe hyperglycemia after 
short-term intensive insulin therapy. Diabetes Care. 2008;31: 1927-32.

181. Tremblay F, Krebs M, Dombrowski L, Brehm A, Bernroider E, Roth E, et al. Overactivation of S6 kinase 1 as a cause of human insulin resistance during increased amino acid availability. Diabetes. 2005;54:2674-84.

182. Pallet N, Legendre C. Adverse events associated with mTOR inhibitors. Expert Opin Drug Saf. 2013;12:177-86.

183. Arriola Apelo SI, Neuman JC, Baar EL, Syed FA, Cummings NE, Brar HK, et al. Alternative rapamycin treatment regimens mitigate the impact of rapamycin on glucose homeostasis and the immune system. Aging Cell. 2016;15:28-38.

184. Vivian A, Fonseca MS, Capehorn SK, Garg EJG, Hansen OH, Holst AG, et al. Reductions in insulin resistance are mediated primarily via weight loss in subjects with type 2 diabetes on Semaglutide. J Clin Endocrinol Metab. 2019;104:4078-86.

185. Lee PC, Ganguly S, Goh SY. Weight loss associated with sodiumglucose cotransporter- 2 inhibition: a review of evidence and underlying mechanisms. Obes Rev. 2018;19:1630-41.

186. Howell JJ, Hellberg K, Turner M, Talbott G, Kolar MJ, Ross DS, et al. Metformin inhibits hepatic mTORC1 signaling via dosedependent mechanisms involving AMPK and the TSC complex. Cell Metab. 2017;25:463-71.

Publisher's note Springer Nature remains neutral with regard to jurisdictional claims in published maps and institutional affiliations. 